\title{
Properties of QBO and SAO Generated by Gravity Waves
}

H. G. Mayr ${ }^{\text {I J. G. Mengel 2. C. A. Reddy }}{ }^{3}$, K. L. Chan ${ }^{4}$. and H. S. Porter ${ }^{5}$

INASA Goddard Space Flight Center, Greenbelt, MD

2SM\&A Corporation, Vienna. VA

${ }^{3}$ Formerly at Vikram Sarabhai Space Center, Trivandrum, India

${ }^{4}$ Hong Kong University of Science and Technology, Hong Kong, China

$5_{\text {Furman University, Greenville, SC }}$

Abstract: We present an extension for the 2D (zonal mean) version of our Numerical Spectral Mode (NSM) that incorporates Hines' Doppler spread parameterization (DSP) for small scale gravity waves $(\mathrm{GW})$. This model is applied to describe the seasonal variations and the semiannual and quasi-biennial oscillations (SAO and QBO). Our earlier model reproduced the salient features of the mean zonal circulation in the middle atmosphere, including the QBO extension into the upper mesosphere inferred from UARS measurements. In the present model we incorporate also tropospheric heating to reproduce the upwelling at equatorial latitudes associated with the Brewer-Dobson circulation that affects significantly the dynamics of the stratosphere as Dunkerton had pointed out. Upward vertical winds increase the period of the $\mathrm{QBO}$ observed from the ground. To compensate for that, one needs to increase the eddy diffusivity and the $\mathrm{GW}$ momentum flux, bringing the latter closer to values recommended in the DSP. The QBO period in the model is 30 months (mo), which is conducive to synchronize this oscillation with the seasonal cycle of solar forcing. Multi-year interannual oscillations are generated through wave filtering by the solar driven annual oscillation in the zonal circulation. Quadratic non-linearities generate interseasonal variations to produce a complicated pattern of variability associated with the QBO. The computed temperature amplitudes for the SAO and $\mathrm{QBO}$ are in substantial agreement with observations at equatorial and extratropical latitudes. At high latitudes, however, the observed QBO amplitudes are significantly larger, which may be a signature of propagating planetary waves not included in the present model. The assumption of hydrostatic equilibrium not being imposed, we find that the effects from the vertical Coriolis force associated with the equatorial oscillations are large for the vertical winds and significant for the temperature variations even outside the tropics but are relatively small for the zonal winds.

\section{Introduction}

The mean zonal circulation of the middle atmosphere near the equator is dominated by the semi-annual oscillation (SAO) with a period of 6 months $(\mathrm{mo})$ related to the seasonal variations in solar heating (e.g., Hirota, 1980) and by the Quasi-biennial oscillation (QBO) with periods around $28 \mathrm{mo}$ (e.g., Reed, 1965). The SAO peaks in the upper stratosphere near $50 \mathrm{~km}$ with 
winds of about $30 \mathrm{~m} / \mathrm{s}$, eastward during equinox and westward during solstice. In the upper mesosphere near $80 \mathrm{~km}$, a second peak is observed with comparable magnitude and opposite phase. The QBO is observed in the lower stratosphere around $30 \mathrm{~km}$ with amplitudes close to 20 $\mathrm{m} / \mathrm{s}$. Such oscillations, in opposite phase, have been observed also in the upper mesosphere (Burrage et al., 1996) with the HRDI instrument on UARS (Hays et al., 1994).

Lindzen and Holton (1968) and Holton and Lindzen (1972) established the principle that wave mean flow interactions can generate a QBO without external time dependent forcing. They invoked a steady source of equatorially trapped planetary waves (i.e., eastward propagating Kelvin waves and westward propagating Rossby gravity wave) to provide the wave forcing through critical level absorption and radiative damping. Plumb (1977) and Plumb and Bell (1982) further elucidated the properties of this mechanism.

In principal, the solar driven meridional circulation can generate semi-annual variations in the stratosphere. Westward momentum advected from the summer to the winter hemisphere produces westward winds at equatorial latitudes during solstice, which is qualitatively consistent with the observed SAO. The small magnitude of the SAO thus generated and its latitudinal extent, however, are not in agreement with observations (Meyer, 1970). The theory of Lindzen and Holton has therefore been extended to explain also the SAO with planetary waves (e.g., Dunkerton, 1979; Holton and Wehrbein, 1980; Mahlman and Umscheid, 1984; Hamilton, 1986).

The planetary waves postulated to drive the equatorial oscillations in the stratosphere are largely dissipated there and cannot affect significantly the dynamics of the upper mesosphere. Lindzen (1981) had shown that in this region of the atmosphere, at higher altitudes, small scale gravity waves (GW) can cause the seasonal variations of the zonal circulation to reverse, and Dunkerton (1982a) proposed this mechanism to explain the observed reversal of the SAO above $70 \mathrm{~km}$.

During the last decade, the role attributed to $\mathrm{GW}$ in the middle atmosphere has become increasingly more important relative to planetary waves. From a modeling study, Hitchman and Leovy (1988) concluded that observed Kelvin waves can account for only $20 \%-70 \%$ of the stratospheric SAO and that GW are likely to be important too, "with Kelvin waves decreasing and gravity waves increasing in relative influence going upward into the mesosphere". With a general circulation model (GCM) that resolves planetary waves but not GW, Hamilton et al. (1995) showed that the observed eastward phase of the stratospheric SAO cannot be simulated and that the amplitude of the QBO is an order of magnitude smaller than observed, suggesting again that $\mathrm{GW}$ are playing a more prominent role.

Small-scale gravity waves (GW) cannot be resolved presently with global-scale models, and parameterization is required to make progress. Lindzen (1981) was the first to develop a parameterization for GW breaking in an attempt to understand the dynamics of the upper mesosphere, which is characterized by anomalous temperatures (lower in summer than in winter) and a concomitant reversal in the zonal circulation. In Lindzen's formulation, a few discrete, independent waves are assumed to become individually unstable and deposit momentum in the background flow. This process has been studied extensively (e.g., Weinstock, 1982; Schoeberl et al., 1983; Schoeberl and Strobel, 1984; Dunkerton, 1982b, c, 1985; Fritts, 1984, 1989; Fritts and Dunkerton, 1985; Schoeberl, 1988), and a number of models (e.g., Holton 1982; Garcia and Solomon, 1985; Gaertner et al., 1983; Geller 1984) demonstrated that it can describe the observed anomalies in the mesosphere.

Following Lindzen (1981), the parameterization of GW interacting with the background flow has been the subject of numerous studies (e.g., Dunkerton, 1982b: McFarlane, 1987; Fritts and 
Lu, 1993; Medvedev and Klaasen, 1995; Hines, 1995a, b). The Doppler Spread

Parameterization (DSP) of Hines (1995a, b), whose theoretical foundation has been developed in a series of papers (Hines 1991a, b; 1993). deals with a spectrum of waves and accounts both for wave-wave and wave-mean-flow interactions. We have incorporated the DSP into our numerical spectral model (NSM), introduced by Chan et al. (1994a. b), and reproduced the salient features of the observed QBO and SAO (Mengel et al.. 1995; Mayr et al., 1997, 1998) including their extensions into the upper mesosphere.

The impetus for the present study has been a paper by Dunkerton (1997), where he emphasizes the importance of vertical winds for the QBO. Vertical winds that are part of the Brewer-Dobson circulation (Brewer, 1949; Dobson, 1956) are comparable in magnitude but opposite to the downward propagation velocity of the QBO (Dunkerton, 1978, 1985). In the presence of such winds, the dynamical forcing required to generate the observed QBO then needs to be much larger (Gray and Pile, 1989; Dunkerton, 1985; Kinnersley and Pawson, 1995).

We present here a revised 2D revision of our NSM that describes the SAO and QBO under the influence of tropospheric heating, which contributes significantly to generate realistic vertical winds in the overlaying stratosphere. In section 2 we present the model. In section 3 we discuss results that describe: (a) the evolution of the model, (b) the properties of QBO related interannual and interseasonal variations, (c) the extension of the QBO and SAO to mid and high latitudes, (d) the role played by the vertical Coriolis force that becomes important at equatorial latitudes. In Section 4 , we discuss and qualify the results and summarize our conclusions.

\section{Model}

The numerical design our Numerical Spectral Model (NSM) has been discussed by Chan et al. (1994) and its recent application to the middle atmosphere and lower thermosphere by Mayr et al. $(1997 \mathrm{a} ; 1998)$. In the following we summarize the features of the NSM that are relevant to the work presented here.

The NSM is time dependent, generally $3 \mathrm{D}$ and fully non-linear. The spectral formulation of the NSM has the advantage of being computationally efficient for low zonal wave numbers, which applies obviously to the $2 \mathrm{D}$ version of the model but to the $3 \mathrm{D}$ version as well that describes tides and large-scale planetary waves having low zonal wavenumbers. The NSM is well suited to study the dynamical components individually and interacting to provide insight. The NSM is simplified in that perturbation theory is applied to compute the wind fields and the temperature and density perturbations of an adopted globally averaged background atmosphere.

The design of the model has several advantages that serve its application with emphasis on dynamics: (i) With the relative temperature perturbations being generally less than $10 \%$, the radiative energy loss from the atmosphere below $120 \mathrm{~km}$ can be formulated in terms of Newtonian cooling that reduces the computational effort significantly. (ii) The NSM is applied efficiently to an atmosphere that extends from the Earth's surface to the top of the thermosphere at $400 \mathrm{~km}$. Well-defined physical boundary conditions then apply, i.e., vanishing vertical and horizontal winds at the ground and vanishing vertical gradients of temperature and horizontal winds at the upper boundary. This assures that the transfer of energy and momentum is seamless without introducing artificial momentum sources and wave reflections. (iii) In a unified framework, the model enables us to assess the effects of regional energy and momentum sources throughout the atmosphere. 
To speed up the computation, the upper boundary of the NSM in its present 2D application has been moved from 400 to $250 \mathrm{~km}$, which is well above the region of primary interest. Numerical tests show that the GW interaction requires small altitude and related time integration steps, chosen to be typically $0.35 \mathrm{~km}$ and 20 minutes respectively. The maximum meridional wave number for the spherical harmonics retained in the model is $l=12$, corresponding to a grid point resolution of about $7.5^{\circ}$, which is sufficient to describe the equatorial oscillations that are confined within $15^{\circ}$ of latitude.

In our earlier model, the zonally averaged component (zonal wavenumber $\mathrm{m}=0$ ) was driven only by solar UV radiation absorbed in the stratosphere and mesosphere (Strobel, 1978) and by EUV radiation absorbed in the thermosphere. In the troposphere below, radiative heating was not accounted for. The troposphere was treated essentially as a large sponge layer that allowed us to implement homogeneous boundary conditions at the Earth's surface. [In our 3D applications of the NSM, however, tides and planetary waves were generated in the troposphere (Mayr et al., 1998, 1999b).]

The model discussed in the present paper differs in that we make an attempt here to describe the tropospheric circulation phenomenologically. The purpose of this modification is primarily to generate more realistic values for the upward motions at low latitudes, which characterize the Brewer-Dobson circulation in the stratosphere and affect significantly the QBO as Dunkerton $(1997,1985)$ had pointed out.

Near the tropopause, the mean zonal winds outside the tropics exhibit eastward jets with peak velocities close to $20 \mathrm{~m} / \mathrm{s}$. The winds vary with season but do not change direction from summer to winter unlike those observed in the stratosphere. The time constants involved are sufficiently long to dampen the seasonal cycle in the solar forcing. To drive this circulation, we adopt a tropospheric heat source, largely balanced by radiative Newtonian cooling, that is assumed for simplicity to be independent of season and peaks at $5 \mathrm{~km}$ altitude and at the equator (described with the lowest order Legendre polynomial, $\mathrm{P}_{2}$ ). The magnitude of this source is chosen to produce zonal winds near the tropopause that are comparable to those observed. More

importantly, this source also enhances significantly the vertical winds in the lower stratosphere to produce realistic values close to $0.3 \mathrm{~mm} / \mathrm{s}$ at $30 \mathrm{~km}$.

We emphasize that our approach to model the rising motions in the stratosphere at low latitudes is phenomenological in nature. Our simplified model of the troposphere does not account for the myriad of complicated physical processes that do occur there such as convection and release of latent energy, which would go far beyond the limited scope of our scientific objective.

\section{Results}

Influence of Tropospheric Source

Inclusion of a tropospheric source as discussed above produces in the model the zonal circulation near December solstice that is presented in Figure 1. In the stratosphere and lower mesosphere it shows the familiar jets that are eastward in winter and westward in summer, and the winds reverse direction above $70 \mathrm{~km}$ as observed. Distinct from our earlier model, Figure 1 now shows also eastward directed zonal jets near the tropopause at $15 \mathrm{~km}$, which are caused by the tropospheric heat source. 
A more important aspect of our present model is that the tropospheric source also generates upward winds at low latitudes, and their five-year average is presented in Figure 2a with long dashed lines. By comparison with a solution without tropospheric heating, shown in short dashed lines, the velocities are now much larger. At $30 \mathrm{~km}$, where the QBO is observed with a downward propagation velocity of about $1.3 \mathrm{~km} / \mathrm{mo}(0.5 \mathrm{~mm} / \mathrm{s})$, the tropospheric heating contributes to upward winds of $0.2 \mathrm{~mm} / \mathrm{s}$ to yield a total of about $0.3 \mathrm{~mm} / \mathrm{s}$. These vertical winds cause a Doppler shift to exceedingly long periods, which essentially stops the QBO as shown in the following.

To provide continuity, we present first in Figure 3a a simulation of the equatorial oscillations in the zonal winds taken from Mayr et al. (1999a). It shows below $40 \mathrm{~km}$ a QBO with a period of $30 \mathrm{mo}$, amplitudes close to $15 \mathrm{~m} / \mathrm{s}$ and a downward propagation velocity of about $1.2 \mathrm{~km} / \mathrm{mo}$, all in reasonable agreement with observations. At higher altitudes near $50 \mathrm{~km}$, the $\mathrm{SAO}$ is apparent with amplitudes close to $25 \mathrm{~m} / \mathrm{s}$ and its phase reverses above $70 \mathrm{~km}$ as observed. [When the SAO is removed, the model also reveals a significant QBO in the upper mesosphere, which has been inferred from UARS (Burrage et al., 1996).]

For comparison, we present in Figure $3 \mathrm{~b}$ the computed oscillations under the influence of the enhanced vertical winds shown with long dashed lines in Figure 2. With the time average component retained, the computed zonal winds are dominated by alternating jets below $40 \mathrm{~km}$. Wind velocities close to $15 \mathrm{~m} / \mathrm{s}$ develop but do not change with time, in contrast to Figure $3 a$ in which the QBO dominates. When the time average component is removed, Figure $3 \mathrm{c}$ reveals the SAO but no QBO. As Dunkerton $(1985,1997)$ pointed out, the QBO is suppressed by upward winds commensurate with the Brewer-Dobson circulation.

We know from the work of Plum and Bell (1986) and from our own analysis (Mayr et al., $1998 \mathrm{a}, \mathrm{b})$ that the period and amplitude of the QBO are significantly affected by eddy viscosity, which is derived in the DSP but is uncertain. To rescue the QBO in the presence of vertical winds that Doppler-shift its period virtually to infinity and prevent it from propagating downwards, the model thus needs to be modified in two ways: (1) The eddy viscosity needs to be enhanced, which decreases the period and amplitude. (2) To compensate for the decrease in amplitude, the GW source needs to be enhanced, which moves us closer to the middle of the parameter range recommended by the DSP.

With Figure 4 , we then present a solution for which the eddy viscosity, $K$, has been increased by a factor of 2.5. The GW source, proportional to the characteristic horizontal wavenumber (see Hines, 1997a, b), has been increased by a factor of 2 to yield $k *=1 / 50\left(\mathrm{~km}^{-1}\right)$ corresponding to a horizontal wavelength of about $300 \mathrm{~km}$. The period of the QBO generated in the model is again $30 \mathrm{mo}$, as in Figure 3 a without tropospheric heat source and with lower $K$ and smaller GW source $\left(k_{*}\right)$. The QBO amplitude now is somewhat larger, closer to the observations. In the following we provide some analytical understanding of the relationship in which the $\mathrm{GW}$ source and eddy viscosity determine the properties of the QBO.

The zonal momentum balance at the equator where the horizontal Coriolis force vanishes can be written as

$$
\rho\left(\frac{\partial \mathbf{U}}{\partial t}+\bar{W} \frac{\partial \mathbf{U}}{\partial z}\right)=K \rho \frac{\partial^{2} \mathbf{U}}{\partial z^{2}}+M S
$$


with standard notations for mass density, zonal winds, time averaged vertical winds, eddy viscosity, $\rho, \mathbf{U}, \bar{W}, K$, respectively. The equatorial oscillations are driven by the momentum source, $M S$, for which we adopt the simplified analytical representation of the DSP given in Mayr et al. (1998b)

$$
M S=A k_{*}\left(\mathbf{U}+\sigma \frac{\mathbf{U}}{|\mathbf{U}|}\right)^{-2}\left[\frac{\partial \mathbf{U}}{\partial z}+\frac{\mathbf{U}}{|\mathbf{U}|} \frac{\partial \sigma}{\partial z}\right]
$$

where $\sigma$ is the GW induced wind variability that grows exponentially with scaleheight $(h), A$ is related to $\sigma$ at the initial height, and $k *$ is the above-mentioned horizontal wavenumber that is adjusted to vary the GW source.

We obtain a simplified solution of Eqs.(1) and (2) in the form $\mathbf{U}=U \exp (i \omega t+i k z)$ with frequency, $\omega$, and vertical wavenumber, $k$. Since the term with quadratic power in Eq.(2) is positive definite and is to first order only a measure of amplitude, the real and imaginary parts yield respectively

$$
\begin{aligned}
& k^{2} K \approx \frac{A k_{*}}{h U(U+\sigma)^{2}} ; \quad U \approx\left[\frac{k *}{K} \frac{A}{h k^{2}}\right]^{1 / 3} \text { for } U>\sigma \\
& \frac{\omega}{k}+\bar{W}=\frac{A k_{*}}{(U+\sigma)^{2}}
\end{aligned}
$$

and substituting Eq.(3) into Eq.(4) yields

$$
\frac{\omega}{k}+\vec{W}=K k^{2} h U
$$

As expected, we learn from Eq.(3) that the wind amplitude, $U$, should increase with increasing $k *$, proportional to the GW source, and decrease with increasing $K$. In the regime of $U$ $>\sigma$ that applies to the present condition, however, the amplitude varies only with $1 / 3$ power. The latter reflects the nonlinear nature of the GW interaction based on the DSP, which is essential for generating the QBO and SAO in our model (Mayr et al., 1998a, b). From Eq.(5), we learn that to first order the downward propagation velocity of the oscillation, $c=\omega / k$, and the related oscillation period, $\tau=2 \pi / \omega$, are related to $\bar{W}, K$, and $U$.

Based on this heuristic analysis, we can readily understand the numerical results earlier discussed. As Eq.(5) demonstrates, the increase in $\vec{W}$ generated by tropospheric heating requires that $K$ be increased in order to maintain reasonable values for the period and zonal wind amplitude of the oscillation. The increase in $K$ on the other hand requires that the $\mathrm{GW}$ source, proportional to $k_{*}$, also be increased in order to maintain the amplitude as Eq.(3) demonstrates.

Properties of Modeled QBO

The numerical model discussed here is highly idealized. The oscillations are generated by a GW source that is time independent; and no account is taken of the Earth's topography, the variability of the troposphere and interactions with the oceans. The QBO generated in our model 
thus reveals persistent and distinct features that are well understood -- yet they are fairly complicated as shown in the following. While the QBO in the real world will be different and more variable, our model illustrates how complicated the oscillations can be even under controlled conditions -- and this we hope may stimulate some observations.

The QBO's both in Figures 3a and 4, with and without tropospheric source, have in common that the period is $30 \mathrm{mo}$, which is also the period for one of the two models discussed by Dunkerton (1997). A period of 30 mo (odd multiple of $6 \mathrm{mo}$ ) is exceptionally well suited for synchronization by the seasonal cycle of the solar forcing.

During solstice conditions, the solar driven meridional circulation advects from the summer hemisphere negative (westward) momentum across the equator. The westward zonal winds thus generated near the equator absorb upward propagating GW, which in turn amplifies the winds. The seasonal cycle in the solar forcing thereby acts as the seed to synchronize the SAO and determine its periodicity. In the same vane, the seasonal cycle and the SAO can act a pacemaker to synchronize the QBO. This is illustrated with Figure 5 (modified version of a figure shown in Mayr et al., 1999a), which reveals the phase relationship between the SAO and QBO based on our numerical results. For the 30-mo QBO, the SAO reinforces in this form both the positive and negative phase of the QBO; while for the 24-mo QBO, the SAO would alternately reinforce and counteract the QBO. Other QBO periods, unrelated to the seasonal cycle, would obviously be even less conducive to synchronization by the solar cycle.

As seen from the discussion in the preceding sections, the QBO period is determined by a number of parameters that are not well known. By carefully tuning the model, we can therefore generate, and have generated, periods that span a considerable range, including $24 \mathrm{mo}, 18 \mathrm{mo}$, and odd periods like 33 mo. Consistent with the explanation put forward in Figure 5, however, we find that a QBO period of 30 mo is generated more readily, and we shall discuss here some of the properties of this oscillation.

With Figure 6 we present at $11^{\circ}$ latitude, removed from the equator, the 364 day (yearly) running average for the computed zonal winds, revealing the QBO and its extension into the upper mesosphere. In addition to the $30-\mathrm{mo} \mathrm{QBO}$, this figure reveals also a periodicity of 60 mo, which is seen in the eastward winds that originate at $100 \mathrm{~km}$ in years 3 and 8 , and extend down to $30 \mathrm{~km}$ in years 5 and 10 . Repeatable features in adjacent westward winds support this periodicity.

In our model, a periodicity of 60 mo can be readily understood. It is the result of GW filtering involving the $\mathrm{QBO}$ and the Annual Oscillation (AO). Waves propagating up through the nodes of the QBO are less attenuated and are therefore more effective in amplifying the AO. The condition for this amplification is determined by $N \tau / 2=n 12$, where $N$ and $n$ are integers, so that the resulting beat period is $\tau_{B}=N \tau / 2=60 \mathrm{mo}$. Unlike the QBO that is to first order hemispherically symmetric, the 60 -mo oscillation is asymmetric with respect to the equator since the asymmetric $\mathrm{AO}$ is involved. [Correspondingly, $\mathrm{GW}$ filtering by the $\mathrm{QBO}$ has been shown to modulate the SAO with a beat period of 30 mo (Mayr et al., 1999a).]

Although the filter applied to produce Figure 6 is crude, it reveals a complicated pattern of variability that cannot be understood solely in terms of the 30 and 60 mo periodicities. Nonlinear processes that involve the QBO, AO, and SAO further complicate the picture. To reveal this complexity and provide understanding, we show with Figure 7 the Fourier amplitudes for the zonal winds at $11^{\circ}$ latitude taken from a computer run that covers 15 years. In addition to the entire spectrum, the symmetric and asymmetric components are presented separately. The spectra reveal the dominant periods of 12 and 6 mo for the AO and SAO respectively that are 
driven by the seasonal cycle in solar heating. The asymmetric component with a period of 4 mo is due to the quadratic non-linearities involving the AO and SAO.

Apart from the periods 12,6 , and 4 , one can readily show that virtually all the other periods in Figure 7 are related to the QBO with a period of 30 mo. As discussed earlier, GW filtering involving the $\mathrm{AO}$ causes the 60 mo oscillation, and all the other periods can be traced to quadratic nonlinear interactions involving the long period 60 mo oscillation, the QBO, $\mathrm{AO}$, and SAO. For example, the asymmetric 20 mo oscillation can be explained with interactions between $\mathrm{QBO}$ and $\mathrm{AO}$, which produce also a period of about 8.6; and the symmetric 15 mo oscillation can be explained with "quadratic" QBO interactions.

Being able thus to identify and explain the periodicities in Figure 7, we can synthesize the oscillations that are related to the QBO, and Figure 8 shows the result at $11^{\circ}$ latitude for periods greater then $6 \mathrm{mo}$. While the $30 \mathrm{mo}$ QBO period clearly dominates below $30 \mathrm{~km}$, interseasonal and other interannual variations become increasingly more important at higher altitudes. Our results illustrate that the combined picture of the QBO related oscillations could be extremely complicated. And for the idealized model presented here, we do understand how this complication can develop. The real world is likely to be even more complicated and much more difficult to understand.

\section{Latitudinal Extensions of QBO and SAO}

Our 2D model describes the wave-induced oscillation in the zonal wind field that is confined largely to the equatorial region where the horizontal Coriolis force is weak. To first order, the QBO can be understood from the zonal momentum budget at the equator (Lindzen and Holton, 1968). In reality, however, the meridional circulation redistributes energy and momentum, which affects the QBO and SAO (Lindzen and Holton, 1968; Holton and Lindzen, 1972; Plumb, 1977; Plumb and Bell, 1982; Dunkerton, 1985, 1997). The meridional circulation also controls the latitudinal extensions of the QBO and SAO in our model that are discussed here.

In Figure 9 we show a snapshot for the computed zonal wind oscillations with periods 6 mo and $30 \mathrm{mo}$, representing the SAO and QBO respectively on January 1 near solstice. As discussed earlier, during this season, the meridional circulation advects westward winds (negative velocities) from the summer hemisphere across the equator into the winter hemisphere, and thus provides the seed and pacemaker for GW to generate the SAO (Figure 9a). At altitudes around $55 \mathrm{~km}$ the zonal winds for the SAO are therefore westward but reverse direction above 70 $\mathrm{km}$ due to GW filtering (Dunkerton, 1980). The SAO is largely confined to equatorial latitudes, where the amplitudes exceed $30 \mathrm{~m} / \mathrm{s}$ comparable to those observed. The QBO in Figure $9 \mathrm{~b}$ is shown during a year where this oscillation tends to be in phase with the SAO, and the same pattern repeats 6 mo later (not shown). The winds for both QBO and SAO are in the opposite directions after 15 mo (not shown). As illustrated with Figure 5, this phase relationship allows the SAO to be the pacemaker for the QBO, to synchronize it with the seasonal cycle and thus influence and determine its periodicity.

Unlike the zonal winds in the SAO and QBO that are largely confined to equatorial latitudes where the horizontal Coriolis force is weak, the associated temperature variations are just as large or larger at mid and high latitudes. This is shown with Figure 10, where we present snapshots for the temperature perturbations in the SAO and QBO. At equatorial latitudes, the computed positive and negative zonal winds in Figure 9 tend to correspond respectively to positive and negative temperature perturbations in Figure 10, which is expected from the quasi geostrophic momentum balance. The latitudinal extensions of the temperature variations, however, are the signatures of large-scale meridional winds driven by (or associated with) the 
wave generated zonal winds of the QBO and SAO at equatorial latitudes. The meridional winds essentially redistribute energy between high and low latitudes. and the resulting adiabatic heating and cooling produces the pressure variations that satisfy the meridional momentum balance. The computed temperature perturbations are as large as $4 \mathrm{~K}$ for the $\mathrm{SAO}$ and $1.5 \mathrm{~K}$ for the QBO.

To illustrate the variability that arises in the temperature field, we show in Figure 11 for $48^{\circ}$ latitude a synthesis of the periods above 6 mo that are associated with the QBO. As in Figure 8, the computed interannual and interseasonal variations are large and produce a complicated pattern that can be understood in terms of GW filtering and non-linear interactions. The QBO like temperature perturbations are propagating down below $50 \mathrm{~km}$. Above that height, however, the asymmetric 5-year oscillation appears to be propagating upward, which must be related to the AO but is not understood in detail.

\section{Vertical Coriolis Force}

The assumption of hydrostatic equilibrium is not imposed in the formulation of our model. Vertical accelerations associated with inertia, advection and Coriolis force are accounted for. Unlike the horizontal component of the Coriolis force, its vertical component does not vanish at the equator but peaks there. So it is at least of academic interest to determine how this force affects the QBO and SAO that are generated in the equatorial region. To address this question, we turned off the vertical Coriolis force and conducted a control experiment with identical initial condition and integration length to provide a comparison with the standard model.

The results of this comparison reveal that the effects from the vertical Coriolis force are generally small for the zonal winds in the QBO and SAO. But the effects are not negligible for the associated temperature variations even outside the tropics, and the effects are large for the vertical winds that are affected more directly by this acceleration.

In Figure 12 we show the monthly average of the computed vertical winds taken as the average at $\pm 4^{\circ}$ latitude for model runs with (a) and without (b) the vertical Coriolis force. Although there are some similarities in the overall pattern, the differences are large.

The vertical winds thus generated by the Coriolis force contribute to the meridional circulation that redistributes energy, mass, and momentum globally. This affects the temperature variations not only at the equator but also at mid and high latitudes as shown in Figure 13 where we compare at $\pm 48^{\circ}$ latitude solutions with and without the vertical Coriolis force. The overall patterns are similar, but there are differences in detail and they are not small.

\section{Discussion and Summary}

As pointed out by Dunkerton (1997), our model results show that the vertical winds generated in the troposphere require a larger $\mathrm{GW}$ source (closer to values recommended by the DSP) to reproduce a QBO with acceptable amplitude and period. Along with the increase in source, the eddy viscosity also had to be enhanced as a simplified heuristic analysis of the momentum budget can explain. The increase in eddy viscosity appears to be consistent with the model of Dunkerton (1997) that requires values 2-3 times larger than those employed by Holton and Lindzen (1972).

The vertical winds associated with tropospheric heating are to a large extent driven by the GW that are released in the model at the Earth's surface. When the wave interaction is suppressed below $15 \mathrm{~km}$, the vertical winds produced are too small. This role attributed to GW is an artifact of the model, since in reality the waves are believed to be generated near the 
tropopause, and the DSP is meant to apply only to the middle atmosphere (Hines, 1997a, b). In this 2D version of our model, GW are effectively taking the place of planetary waves that propagate through the troposphere and interact with the background winds in the region.

A related other artifact of the model is that the adopted eddy viscosity, $K$, is tied to the $\mathrm{GW}$ dissipation throughout the atmosphere. This implies that $K$ continues to decrease exponentially all the way down to the surface, which is unrealistic considering that the troposphere is controlled by convection and a host of other processes that are not accounted for. Effectively our model thus underestimates the eddy dissipation in the troposphere.

The computed QBO in our model extends down into the troposphere, which is contrary to observations (e.g., Andrews et al., 1987). A number of reasons may account for that such as the adopted wave forcing and small eddy viscosity. But the dominant factor may be that our model does not produce large enough vertical winds below the tropopause, which are generated presumably by convection. While the dynamics adopted in the present model for the troposphere is artificial, it serves the purpose to generate in the equatorial stratosphere the vertical winds that are part of the Brewer-Dobson circulation and as such affect the QBO significantly (Dunkerton, 1997).

The period of the QBO presented here is close to $30 \mathrm{mo}$, and the argument is compelling as Figure 5 illustrates that such a periodicity is well suited to synchronize the QBO with the seasonal cycle of solar forcing. Dunkerton (1997) also presented a QBO with such a period, in addition to $24 \mathrm{mo}$, and is pointing out that small changes in the wave forcing were shifting the period from one to the other. In our present model it is not that easy to shift the period away from $30 \mathrm{mo}$. The reason for this is that $30 \mathrm{mo}$ in our case also happens to be the "eigenperiod" that is generated in the absence of seasonal variations in the solar heating, and this is purely coincidental. A small increase in eddy viscosity would decrease this eigenperiod to bring it closer to $24 \mathrm{mo}$, and we believe that the seasonal cycle may then act as a pacemaker to pull the oscillation either to 24 or 30 mo as discussed by Dunkerton (1997).

With a QBO of 30 mo, wave filtering modulates the SAO with the same period (Mayr et al., 1999a). As discussed in the present paper, wave filtering also modulates the AO with a period of $60 \mathrm{mo}$, and this oscillation is hemispherically asymmetric. The picture that emerges thus reveals a large degree of variability. While the yearly averages of the computed zonal winds are typically about $10 \mathrm{~m} / \mathrm{s}$ at $11^{\circ}$ latitude (Figure 6), the QBO related winds vary considerably and can exceed $30 \mathrm{~m} / \mathrm{s}$ as shown in Figure 8 . Some of this variability is caused by non-linearities involving the SAO that peaks near $55 \mathrm{~km}$ with an amplitude of $35 \mathrm{~m} / \mathrm{s}$ (Figure $9 \mathrm{a}$ ) and is somewhat larger than observed (Angell and Korshover, 1970; Hirota, 1980). [Earlier results have shown, however, that the $\mathrm{SAO}$ is reduced in a $3 \mathrm{D}$ version of the model where tides and planetary waves absorb some of the GW that in $2 \mathrm{D}$ would go into generating the equatorial oscillations (Mayr et al., 1999a).]

The extension of the QBO into the upper mesosphere as shown in our model (Figure 6) has been observed on UARS (Burrage et al., 1995). As is the case for the SAO, the phase of the QBO reverses at altitudes around $70 \mathrm{~km}$. At altitudes around $60 \mathrm{~km}$ in year 4 , the eastward winds in the QBO absorb preferentially the waves propagating to the east. The surplus of westward propagating waves then causes the westward phase of the QBO at altitudes around 90 $\mathrm{km}$. As shown in Figure 6, a similar kind of process appears to be active at altitudes around 45 $\mathrm{km}$ where the QBO phase tends to reverse. The QBO is observed to peak at altitudes near $30 \mathrm{~km}$ (e.g., Reed, 1965: Angell and Korshover, 1965), and these early observations indicated that the oscillation then increases above the stratopause. Angell and Korshover (1970) also reported that 
the QBO at 50 and $60 \mathrm{~km}$ are almost out of phase, which is qualitatively consistent with our model results.

The computed zonal winds of the SAO in Figure 9a are consistent with the observations of Angell and Korshover (1970) that show the winds outside the tropics being relatively small and having a phase virtually independent of latitude. In contrast to the observations of Angell and Korshover (1970), however, the QBO winds in our model (Figure 9b) are close to zero outside the tropics. Poleward propagating planetary waves that are filtered by the zonal circulation of the QBO may carry that signature to higher latitudes (R. A. Plum, private communication) -- a process that is not accounted for in the present model.

The observed temperature variations for the SAO (Angell and Korshover, 1970) show the largest amplitudes (close to $4 \mathrm{~K}$ ) at high latitudes, which is in substantial agreement with our results (Figure 10a). For the QBO (Figure 10b), the computed temperature amplitudes also agree with observations at equatorial and mid latitudes but are significantly smaller at high latitudes (Angell and Korshover, 1970), which indicates again that poleward propagating planetary waves, not accounted for in the present model, are likely to be important.

The conclusions are summarized:

1.) The 2D version of our Numerical Spectral Model has been extended to incorporate tropospheric heating with the aim to reproduce the upwelling at equatorial latitudes that characterizes the Brewer-Dobson circulation in the lower stratosphere. As pointed out by Dunkerton $(1997,1985)$, the upward vertical winds thus generated are comparable to the downward propagation velocity of the QBO and change significantly the dynamics. To generate a realistic QBO in the present model, the eddy diffusivity had to be enhanced by more than a factor of two. And to compensate for that, the GW source had to be increased by a factor of two, moving the characteristic horizontal wavelength closer to the middle of the range recommended by the DSP.

2.) The QBO period generated in our model is close to $30 \mathrm{mo}$, which is well suited for synchronizing this oscillation with the seasonal cycle of solar forcing.

3 ). Gravity wave filtering by the QBO produces a large modulation of the SAO amplitude having a period of 2.5 years, that of the QBO. Such filtering also modulates the AO to produce a significant 5 -year periodicity that is hemispherically asymmetric.

4.) Originating from the QBO, GW filtering and the quadratic non-linearities in the model generate variations with interannual and interseasonal time scales that become increasingly more important in the mesosphere at higher altitudes.

5.) For the SAO, the computed amplitudes of zonal winds and temperature variations at the equator and outside the tropics are comparable to those observed.

6.) The model reproduces for the QBO the observed zonal winds and temperature perturbations at equatorial latitudes. Compared with observations, the computed zonal winds in the QBO are close to zero outside the tropics; and at high latitudes, the modeled temperature variations are also smaller. This indicates that poleward propagating planetary waves, not accounted for in the present $2 \mathrm{D}$ model, are likely to be important.

7.) Our model is not assumed to be in hydrostatic equilibrium, and the vertical Coriolis force associated with the equatorial SAO and QBO affect significantly the vertical winds and temperature variations even outside the tropics; but the effects on the zonal winds are relatively small. 


\section{References}

Allen, S. J., and R. A. Vincent, Gravity wave activity in the lower atmosphere: Seasonal and latitudinal variations, J. Geophys. Res., 100, 1327 (1995).

Angell, J. K., and J. Korshover, A note on the variation with height of the quasi-biennial oscillation, J. Geophys. Res., 70, 3851 (1965).

Angell, J. K., and J. Korshover, Qusi-biennial, annual, and semi-annual zonal wind and temperature harmonic amplitudes and phases in the stratosphere and lower mesosphere of the northern hemisphere, J. Geophys. Res., 75, 543 (1970).

Andrews, D. G., J. R. Holton, and C. B. Leovy, Middle Atmosphere Dynamics, Academic, San Diego, Ca. (1987).

Burrage, M. D., R. A, Vincent, H. G. Mayr, W. R. Skinner, N. F. Arnold, and P. B. Hays, Longterm variability in the equatorial middle atmosphere zonal wind, J. Geophys. Res., 101, 12847 (1996).

Chan, K. L., H. G. Mayr, J. G. Mengel, and I. Harris, A 'stratified' spectral model for stable and convective atmospheres, J. Comput. Phys., 113, 165 (1994a).

Chan, K. L., H. G. Mayr, J. G. Mengel, and I. Harris, A spectral approach for studying middle and upper atmospheric phenomena, J. Atmos. Terr. Phys., 56, 1399 (1994b).

Chan, K. L., H. G. Mayr, J. G. Mengel, and I. Harris, A numerical spectral model for the mean zonal circulation and the tides in the middle and upper atmosphere, Geophysical Monograph 87, The Upper Mesosphere and Lower Thermosphere: A Review of Experiment and Theory, Eds. R. M. Johnson and T. L. Killeen, 265 (1995)

Dickinson, R. E., Method of parameterization for infrared cooling between altitudes of 30 and 70 km, J. Geophys. Res., 78, 4451 (1973).

Dunkerton, T. J., On the mean meridional mass motions of the stratosphere and mesosphere, $J$. Atmos. Sci., 35, 2325 (1978).

Dunkerton, T. J., On the role of the Kelvin wave in the westerly phase of the semiannual zonal wind oscillation, J. Atmos. Sci., 36, 32 (1979).

Dunkerton, T. J., Theory of the mesopause semiannual oscillation, J. Atmos. Sci., 39, 2681 (1982).

Dunkerton, T. J., A two-dimensional model of the quasi-biennial oscillation, J. Atmos. Sci., 42 , 1151 (1985).

Dunkerton, T. J., The role of gravity waves in the quasi-biennial oscillation, J. Geophys. Res., 102, 26053 (1997).

Dunkerton, T. J., and D. P. Delisi, Interaction of the quasi-biennial oscillation and the stratopause semiannual oscillation, J. Geophys. Res., 102, 26107 (1997).

Fels, S. B., A parameterization of scale-dependent radiative damping rates in the middle atmosphere, J. Atmos. Sci, 39, 1141 (1982).

Fritts, D. C., Gravity wave saturation in the middle atmosphere: A review of theory and observations, Rev. Geophys., 22, 275 (1984).

Fritts, D. C., and T. J. Dunkerton, Fluxes of heat and constituents due to convectively unstable gravity waves, J. Atmos. Sci., $42,549-556$ (1985).

Fritts, D. C., A review of gravity wave saturation processes, effects and variability in the middle atmosphere, Pure Appl. Geophys., 130, 343 (1989). 
Garcia, R. R., and S. Solomon. The effect of breaking gravity waves on the dynamics and chemical composition of the mesosphere and lower thermosphere, J. Geophys. Res., 90, 3850 (1985).

Garcia, R. R., T. J. Dunkerton. R. S. Lieberman, and R. A. Vincent, Climatology of the semiannual oscillation of the tropical middle atmosphere, J. Geophys. Res., 102, 26017 (1997).

Gaertner, V. M. Memmesheimer, and P. W. Blum, A zonally averaged dynamical model for the middle atmosphere including gravity wave mean flow interaction, 1, Solstice condition, Planet. Space Sci., 31, 1465 (1983).

Geller, M. A., Modeling the middle atmosphere circulation, Dynamics of the Middle Atmosphere, Ed. J. R. Holton and D. Matsuno, 467, Terra pub. Tokyo (1984).

Hamilton, K., R. J. Wilson, J. D. Mahlman, and L. J. Umscheid, Climatology of the SKYHI troposphere-stratosphere-mesosphere general circulation model, J. Atmos. Sci., 52, 5 (1995).

Hamilton, K., Dynamics of the stratospheric semi-annual oscillation, J. Meteorol. Soc. Jpn., 64, 227 (1986).

Hays, P. B., V. J. Abreu, M. E. Dobbs, D. A. Gell, H. J. Grassl, and W. R. Skinner, The highresolution Doppler imager on the Upper Atmosphere Research Satellite, J. Geophys. Res., 98, 10713 (1993).

Hines, C. O., Doppler-spread parameterization of gravity-wave momentum deposition in the middle atmosphere, 1, Basic formulation, J. Atmos. Solar Terr. Phys., 59, 371 (1997a).

Hines, C. O., Doppler-spread parameterization of gravity-wave momentum deposition in the middle atmosphere, 2, Broad and quasi monochromatic spectra, and implementation, J. Atmos. Solar Terr. Phys., 59, 387 (1997b).

Hirota, I. Observational evidence of the semiannual oscillation in the tropical middle atmosphere - a review, Pure Appl. Geophys., 118, 217 (1980).

Hitchman, M. H., and C. B. Leovy, Estimation of the Kelvin wave contribution to the semiannual oscillation, J. Atmos. Sci., 45, 1462 (1988).

Holton, J. R., and R. S. Lindzen, An updated theory for the quasi-biennial cycle of the tropical stratosphere, J Atmos. Sci., 29, 1076 (1972).

Lindzen, R. S., and J. R. Holton, A theory of the quasi-biennial oscillation, J. Atmos. Sci., 25, 1095 (1968).

Lindzen R. S., Turbulence and stress due to gravity wave and tidal breakdown, J. Geophys., Res., 86, 9707-9714 (1981).

Mahlman, J. D., and L. J. Umscheid, Dynamics of the middle atmosphere: successes and problems of the GFDL "SKYHI" general circulation model, in Dynamics of the middle atmosphere, J. R. Holton and T. Matsuno, eds., 501 Terrapub. Tokyo (1984).

Mayr, H. G, J. G. Mengel, C. O. Hines, K. L. Chan, N. F. Arnold, C. A. Reddy, and H. S. Porter, The gravity wave Doppler spread theory applied in a numerical spectral model of the middle atmosphere, 2, Equatorial oscillations, J. Geophys. Res., 102, 26093 (1997).

Mayr, H. G, J. G. Mengel, and K. L. Chan, Equatorial oscillations maintained by gravity waves as described with the Doppler Spread Parameterization: I. Numerical experiments, J. Atmos. Solar Terr. Phys., 60, 181 (1998a).

Mayr, H. G, H. E. Hartle, and K. L. Chan, Equatorial oscillations maintained by gravity waves as described with the Doppler Spread Parameterization: II. Heuristic analysis, J. Atmos. Solar Terr. Phys., 60, 201 (1998b). 
Mayr, H. G, J. G. Mengel, C. A. Reddy, K. L. Chan, and H. S. Porter, Thr role of gravity waves in maintaining the QBO and SAO at equatorial latitudes, $A d v$. Space Sci., in press (1999a).

Mayr, H. G, J. G. Mengel, C. A. Reddy, K. L. Chan, and H. S. Porter, Thr role of gravity waves in maintaining the QBO and SAO at equatorial latitudes, $A d v$. Space Sci., in press (1999b).

Mengel, J. G., H. G. Mayr, K. L. Chan, C. O. Hines, C. A. Reddy, N. F. Arnold, and H. S. Porter, Equatorial oscillations in the middle atmosphere generated by small scale gravity waves, Geophys. Res. Lett., 22 , 3027 (1995).

Plumb, R. A., The interaction of two internal waves with the mean flow: Implications for the theory of the quasi-biennial oscillation, J. Atmos. Sci., 34, 1847 (1977).

Plumb, R. A., and R. C. Bell, A model of the quasi-biennial oscillation on an equatorial betaplane, Q. J. R. Meteorol. Soc., 108, 335 (1982).

Reddy, C. A., and L. Vijayan, Annual and semiannual oscillations in the equatorial middle atmospheric winds, Adv. Space Res., 13, 373 (1993).

Reed, R. J., The quasi-biennial oscillation of the atmosphere between 30 and $50 \mathrm{~km}$ over Ascension Island, J. Atmos. Sci., 22, 331 (1965).

Reed, R. J., Zonal wind behavior in the equatorial stratosphere and lower mesosphere, J. Geophys. Res., 71, 4223-4233 (1966).

Schoeberl, M. R., and D. F. Strobel, The zonally averaged circulation of the middle atmosphere, $J$. Atm. Sci, 35, 577, 1978

Schoeberl, M. R., D. F. Strobel, and A. J. Apruzese, A numerical model of gravity wave breaking and stress in the mesosphere, J. Geophys. Res., 88, 5249 (1983).

Schoeberl, M. R., and D. F. Strobel, Nonzonal gravity wave breaking in the winter mesosphere, Dynamics of the Middle Atmosphere, Ed. J. R. Holton and D. Matsuno, 45, Terra pub. Tokyo (1984).

Schoeberl, M. R, A ray tracing model of gravity wave propagation and breakdown in the middle atmosphere, J. Geophys. Res., 90, 7999 (1985).

Schoeberl, M. R, Dynamics of the middle atmosphere, Rev. Geophys., 25, 501 (1987).

Schoeberl, M. R., A model of stationary gravity wave break down with convective adjustment $J$. Atm. Sci., 45, 980 (1988).

Strobel, D. F., Parameterization of atmospheric heating rate from 15 to $120 \mathrm{~km}$ due to $\mathrm{O} 2$ and $\mathrm{O} 3$ absorption of solar radiation, J. Geophys. Res., 83, 7963 (1978).

Takahashi, M., and B. A. Boville, A three-dimensional simulation of the equatorial quasibiennial oscillation, J. Atmos. Sci., 49, 1020 (1992).

Vijayan, L. and C. A. Reddy, Radiative damping of equatorial waves in the middle atmosphere, Q. J. Roy. Met. Soc.,(London), 20, 1323 (1994)

Wehrbein, W. M., and C. B. Leovy, An accurate radiative heating and cooling algorithm for use in a dynamical model of the middle atmosphere, J. Atmos. Sci., 39, 1532 (1982). 


\section{Figure Captions}

Figure 1. Multi-year average of computed zonal winds for December solstice with original GW parameterization and eddy diffusivity but with tropospheric heat source. In contrast to the earlier model, zonal jets are now generated near the tropopause.

Figure 2. Multi-year average of computed vertical winds $(\mathrm{mm} / \mathrm{s})$ at $4^{\circ}$ latitude for models: without tropospheric heat source (short dashed line), with heat source (long dashed line), with tropospheric heat source and larger GW source and eddy viscosity (solid line) that apply to the model results discussed in detail.

Figure 3. (a) Monthly average of computed zonal winds at $4^{\circ}$ latitude, taken from the earlier model (Mayr et al., 1999a). The GW source is proportional to the characteristic horizontal wavenumber taken to be $k *=1 / 100\left(\mathrm{~km}^{-1}\right)$. (b) Same as (a) but obtained with tropospheric heating that produces the upwelling shown in Figure 2 (long dashed line). At altitudes below 40 $\mathrm{km}$ where the QBO dominates strong zonal jets develop that alternate with altitude (equivalent to a period that is virtually infinite). (c) Same as (b) but with the mean winds removed, showing the $\mathrm{SAO}$ but no QBO.

Figure 4. Monthly average of computed zonal winds (time average removed) at $4^{\circ}$ latitude obtained with tropospheric heating and with factor of 2 larger GW source $\left[k_{*}=1 / 50\left(\mathrm{~km}^{-1}\right)\right.$ or $\lambda$ * $\approx 300 \mathrm{~km}$ ] and factor of 2.5 larger eddy viscosity, $K$, for which the prevailing vertical winds are shown in Figure 2 (solid line).

Figure 5. Schematic, illustrating for the equator the relationship between the SAO or the seasonal cycle and the QBO with periods of 30 and 24 mo. Solid and dashed lines indicate when the QBO and SAO are in phase and out of phase respectively, which promotes and opposes synchronization respectively.

Figure 6. Yearly average of zonal winds (time average removed) at $11^{\circ}$ latitude, revealing the QBO and its extension into the upper mesosphere. In addition to the pronounced 30-mo QBO, which extends into the upper mesosphere, a 60 -mo oscillation is also evident. The latter is the signature of $\mathrm{GW}$ filtering by the $\mathrm{QBO}$ and concomitant modulation of the $\mathrm{AO}$.

Figure 7. Fourier spectra of the zonal winds at $11^{\circ}$ latitude obtained from a computer run spanning 15 model years: (a) complete spectrum; (b) spectrum of hemispherically symmetric components (including SAO and QBO); (c) spectrum of hemispherically asymmetric components (including $\mathrm{AO}$ ). Except for the periods 12,6,4, and 3 mo that are related to the seasonal cycle, all other periods are caused by the QBO.

Figure 8. Zonal winds at $11^{\circ}$ latitude obtained by synthesizing the periods (Figure 7) longer than $6 \mathrm{mo}$, which are caused by the QBO, its wave filtering and its non-linear interactions with the $\mathrm{AO}$ and $\mathrm{SAO}$. Note that the QBO in the stratosphere produces in the mesosphere at higher altitudes an increasingly complicated pattern of interseasonal and interannual variations. The resulting winds are much larger than those shown in Figure 6. 
Figure 9. Snapshots of the zonal winds for: (a) $6 \mathrm{mo}$ (SAO) and (b) $30 \mathrm{mo}$ (QBO) on January 1 (near solstice) during a time when the QBO and SAO are in phase at altitudes between 45 and 65 $\mathrm{km}$. The same phase relationship occurs again 6 mo later and then again 15 and 21 mo later with opposite phase, as illustrated in Figure 5. The latitudinal extent of the QBO (b) broadens with increasing altitude, but the winds are virtually zero outside the tropics. The SAO (a), however, does extend to high latitudes.

Figure 10. Same as Figure 9 but for the temperature variations. Unlike the zonal winds, the temperature variations in the QBO extend with significant amplitudes to high latitudes, and in the $\mathrm{SAO}$ the temperature variations are larger at high latitudes than at the equator.

Figure 11. Synthesis of QBO related temperature variations at mid latitudes, analogous to Figure 8. A complicated pattern of interseasonal and interannual variations is apparent in which the temperature can vary by as much as $3 \mathrm{~K}$, much larger than the 30 mo oscillation (QBO) in Figure 10 that is at most $1 \mathrm{~K}$.

Figure 12. Monthly average of the hemispherically symmetric component (eliminating the AO) of vertical winds at $4^{\circ}$ latitude computed with (a) and without (b) the vertical Coriolis force. While similar patterns are apparent overall, the differences are large.

Figure 13. Same as Figure 12 but for the computed temperature variations at $48^{\circ}$ latitude. Compared to Figure 12, the differences are much smaller but still significant. For the zonal winds, however, the effect of the vertical Coriolis force is negligible. 


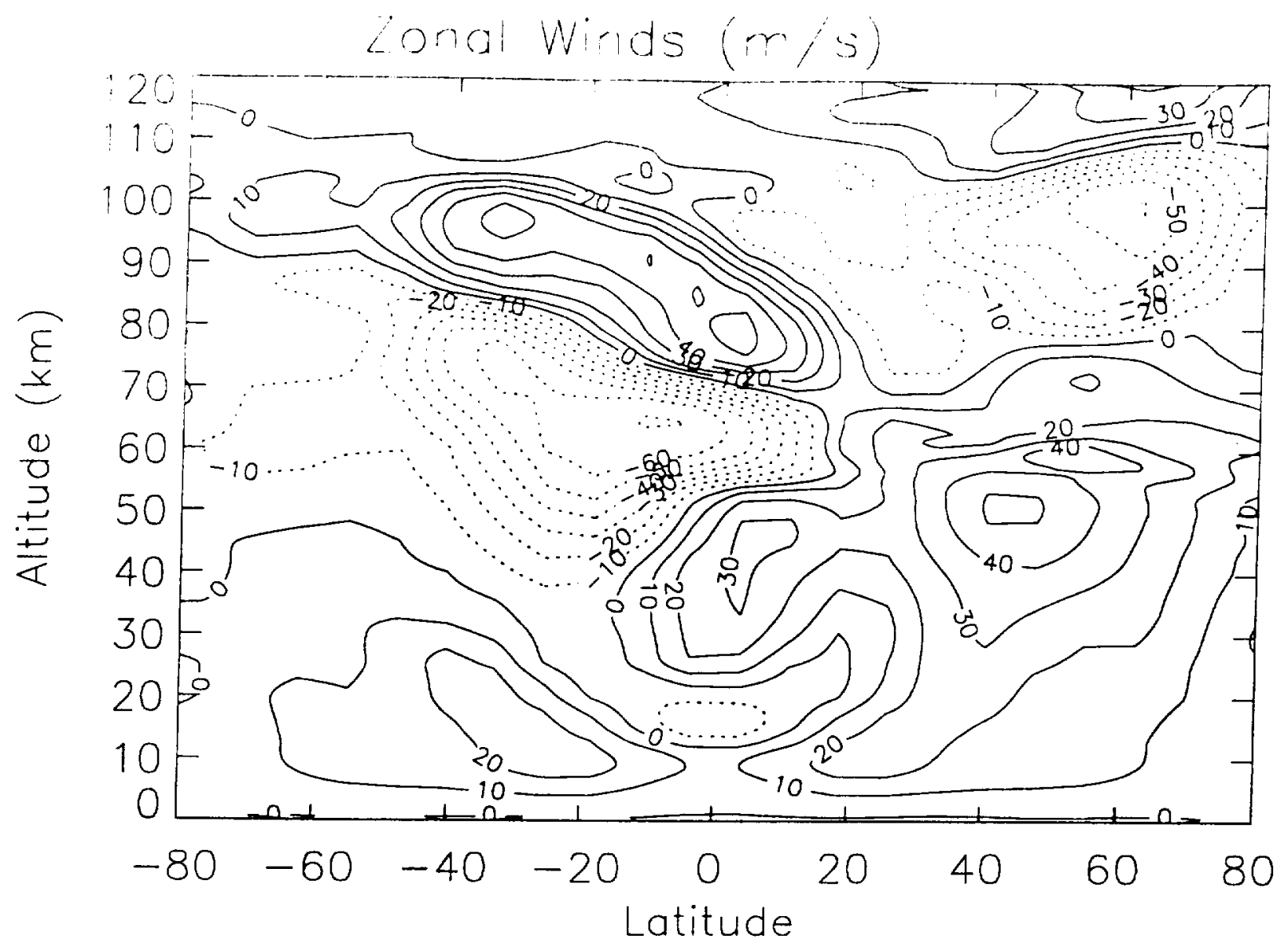

Figure 1 


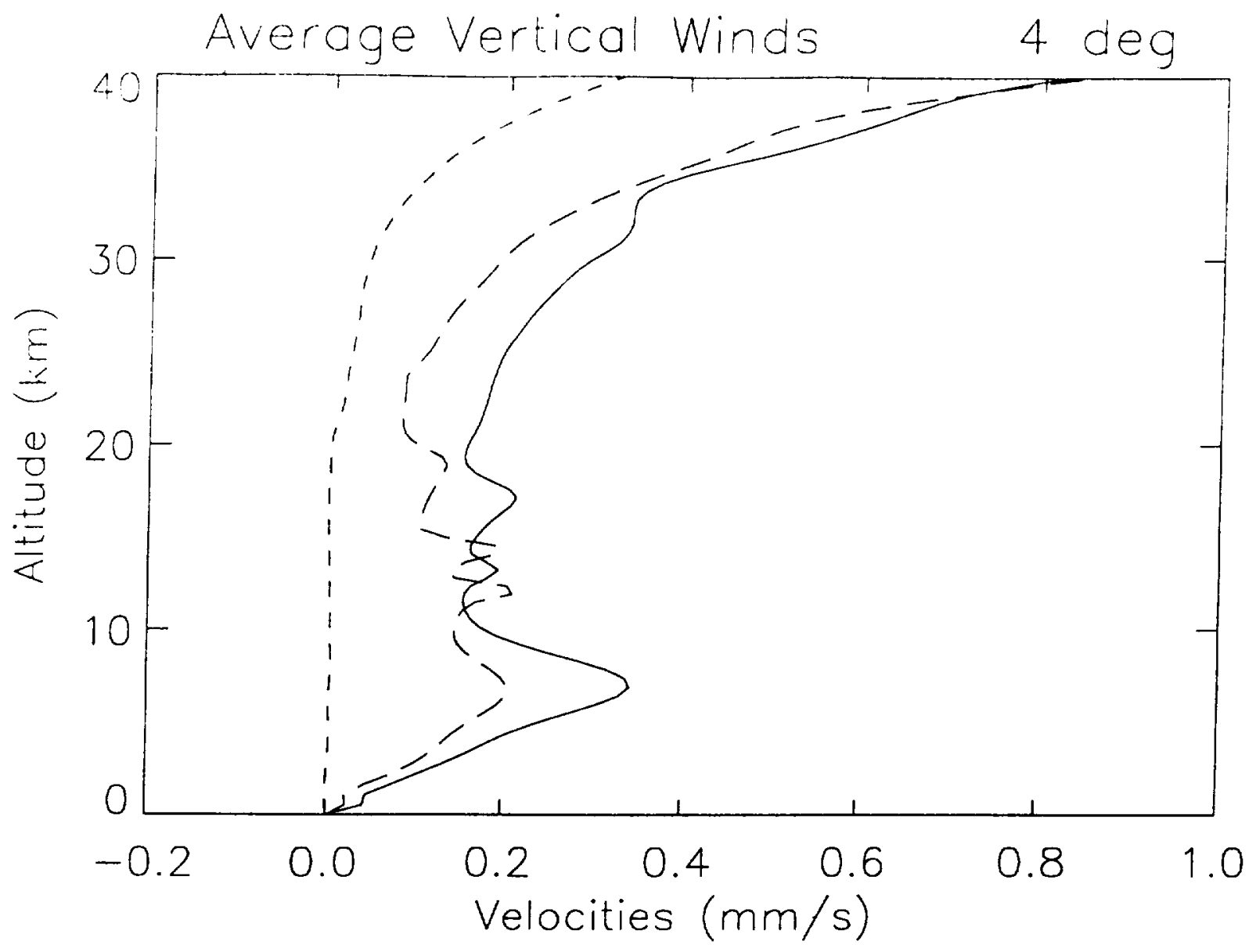

Figure 2 


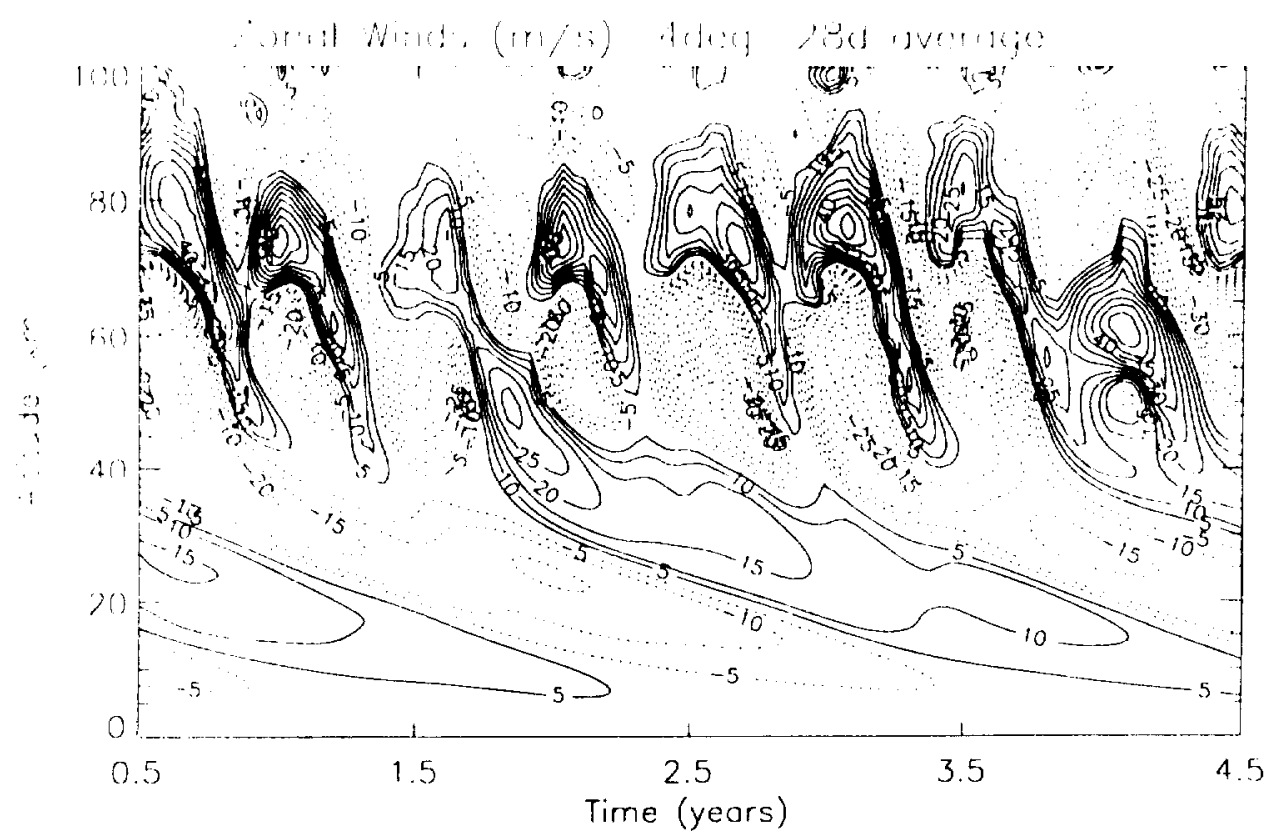

a

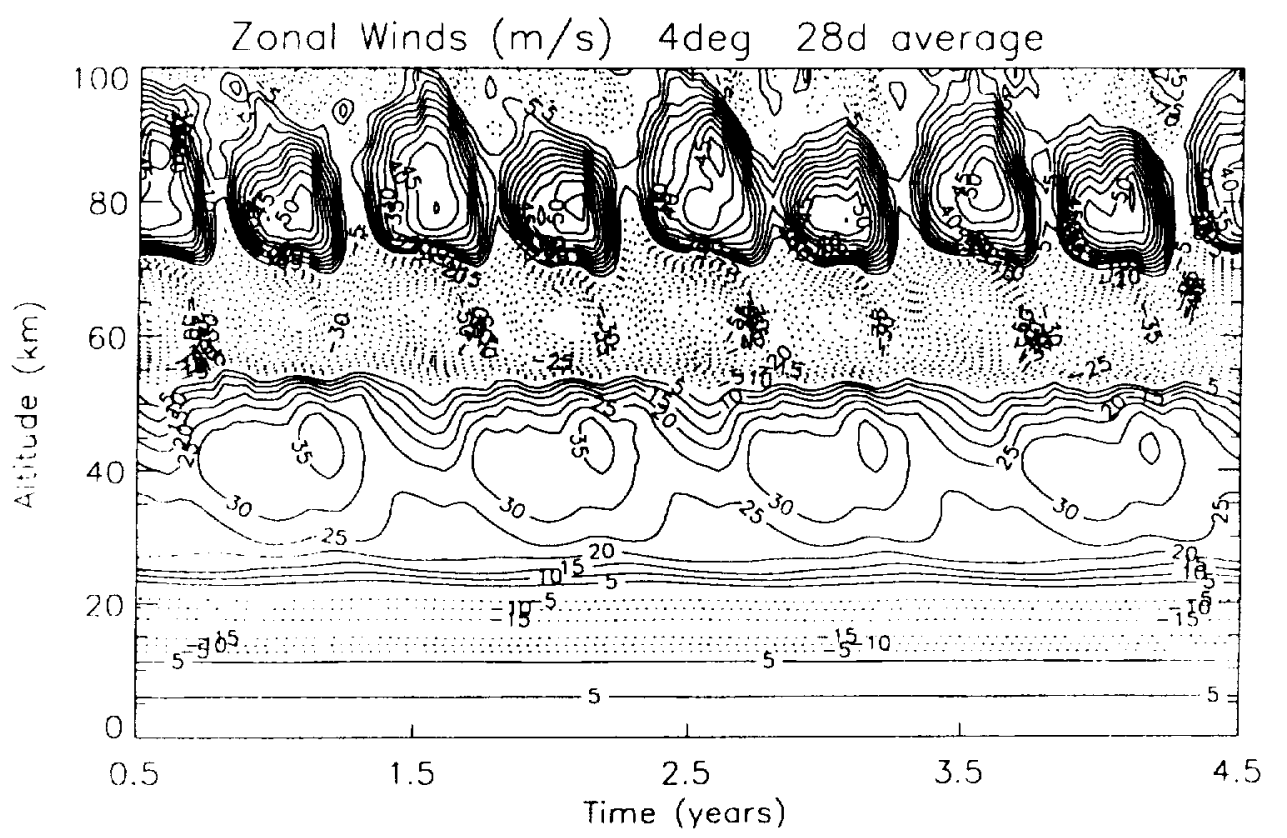

b

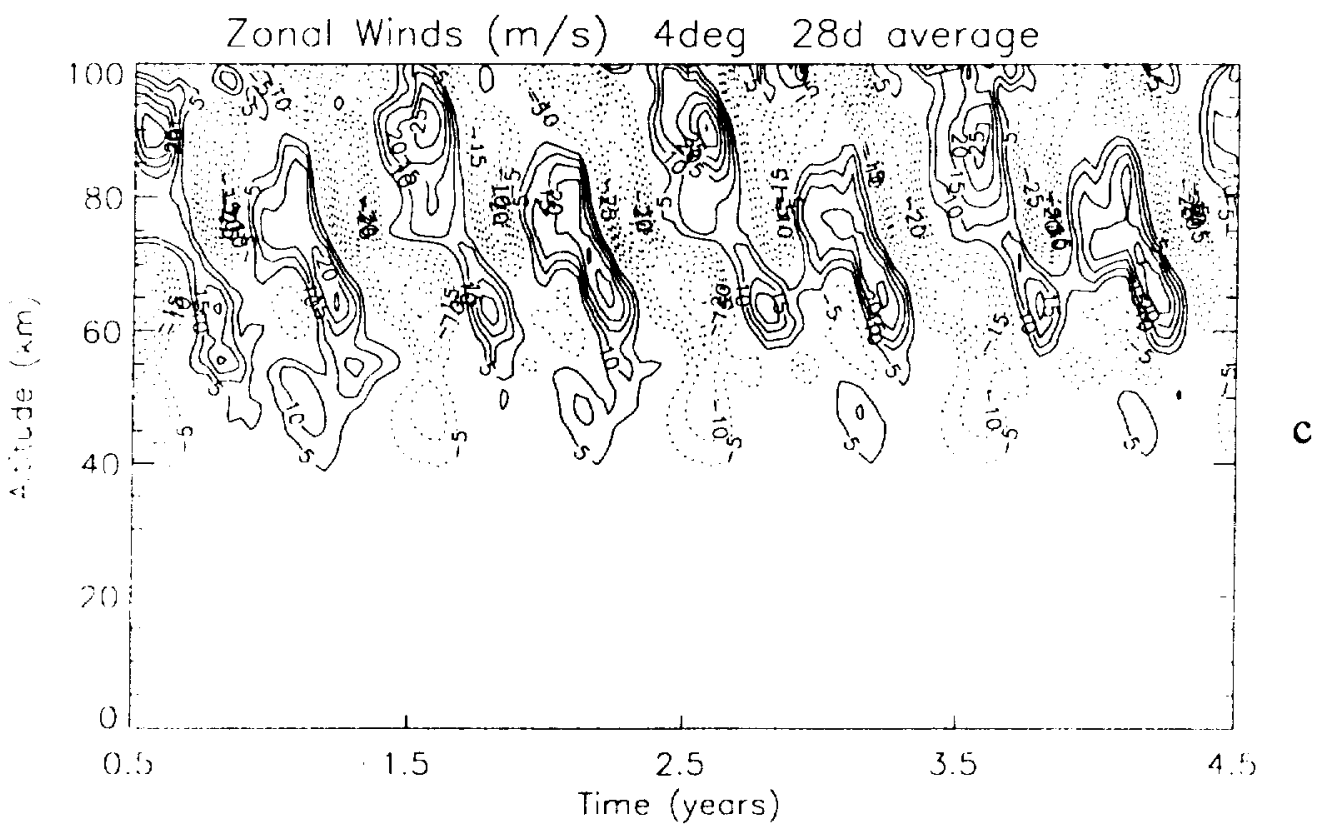

Figure 3 


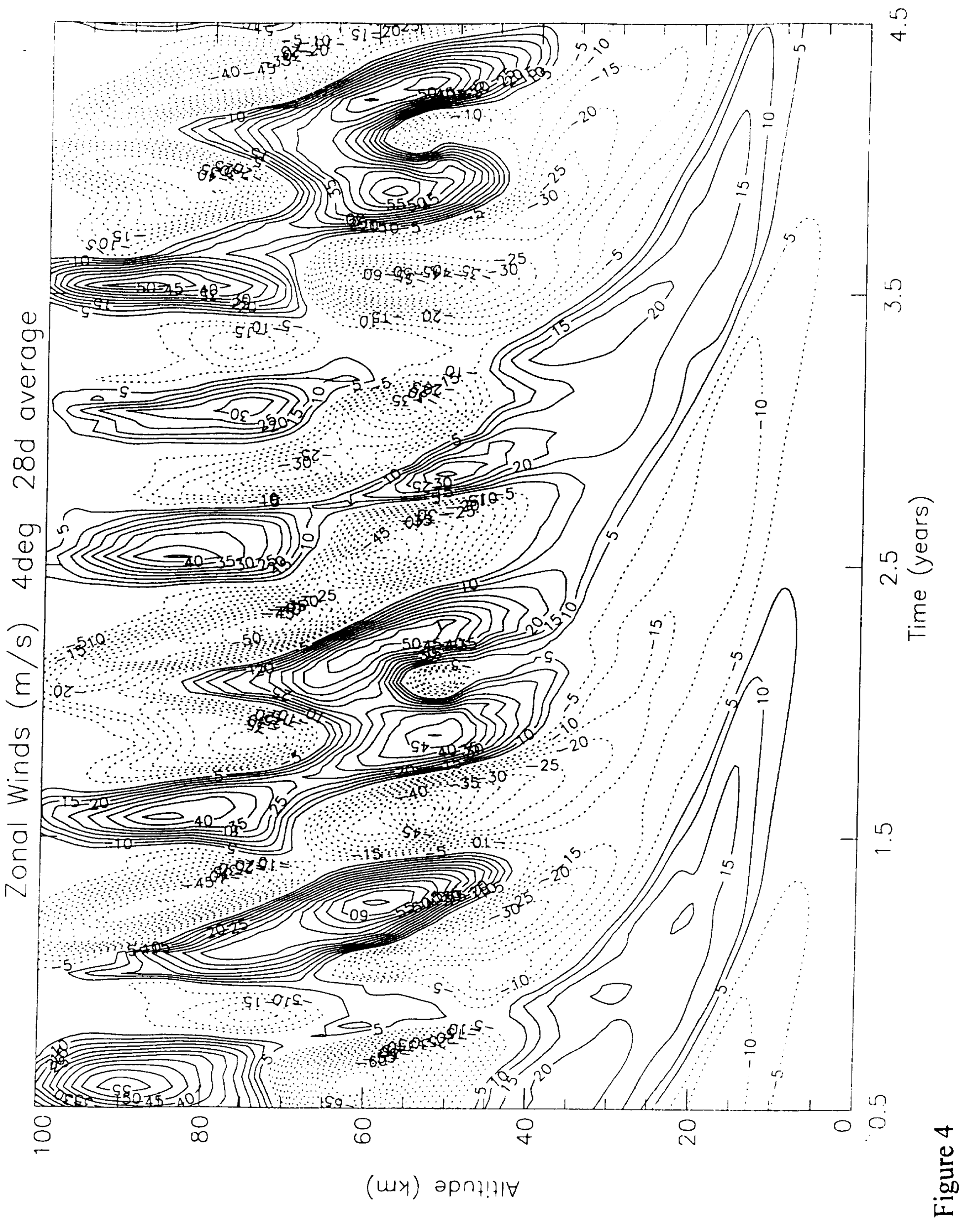




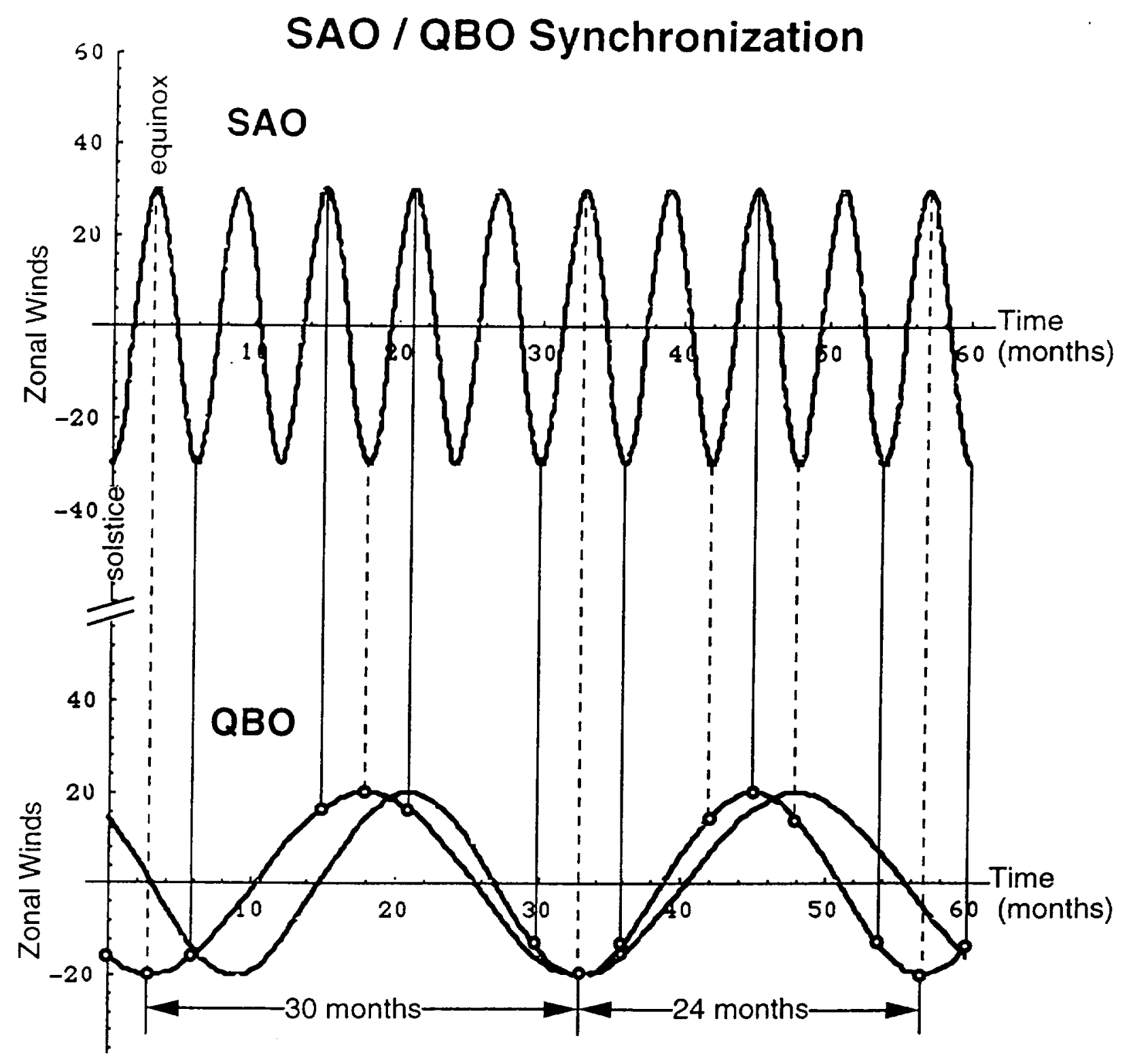

Figure 5 


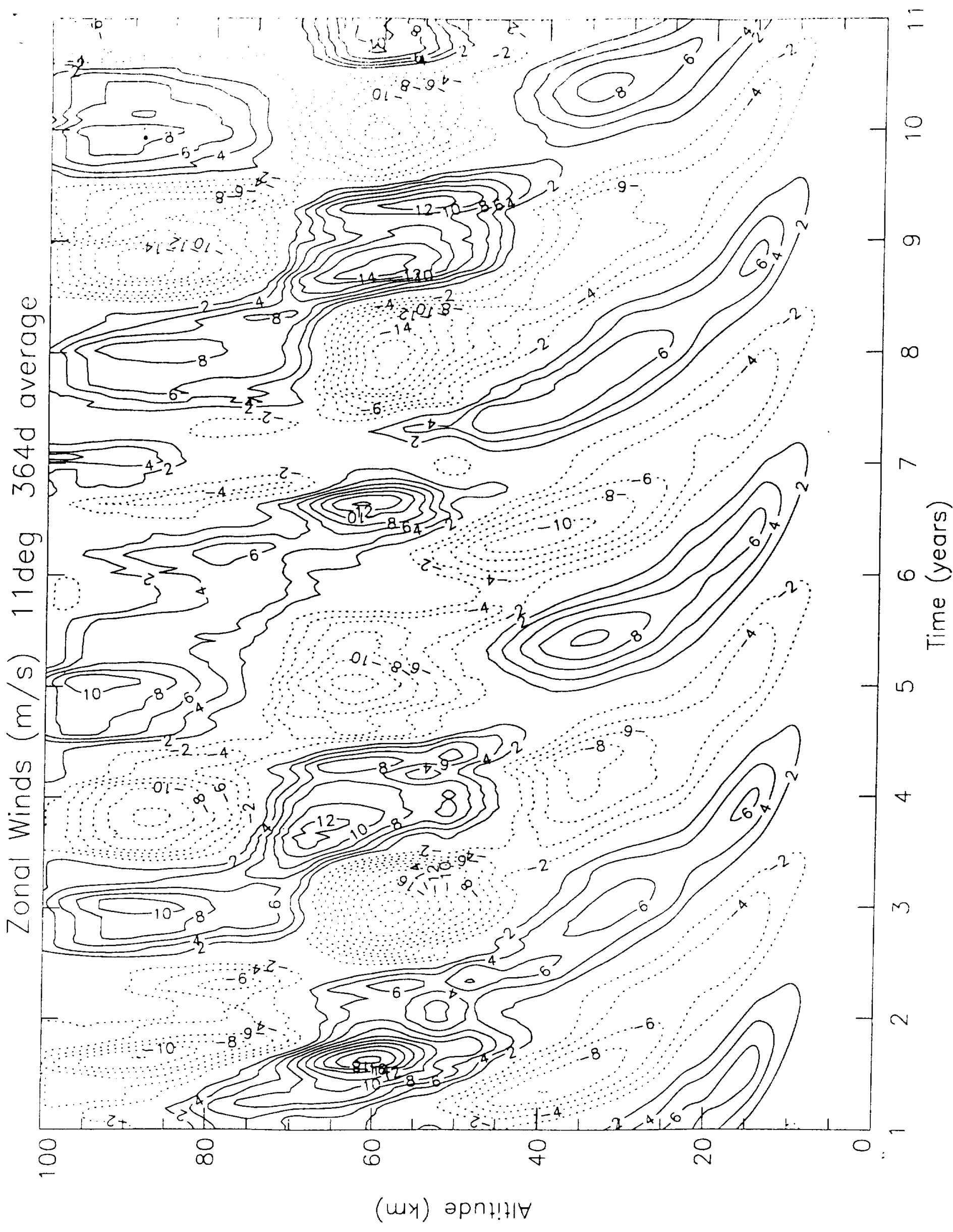




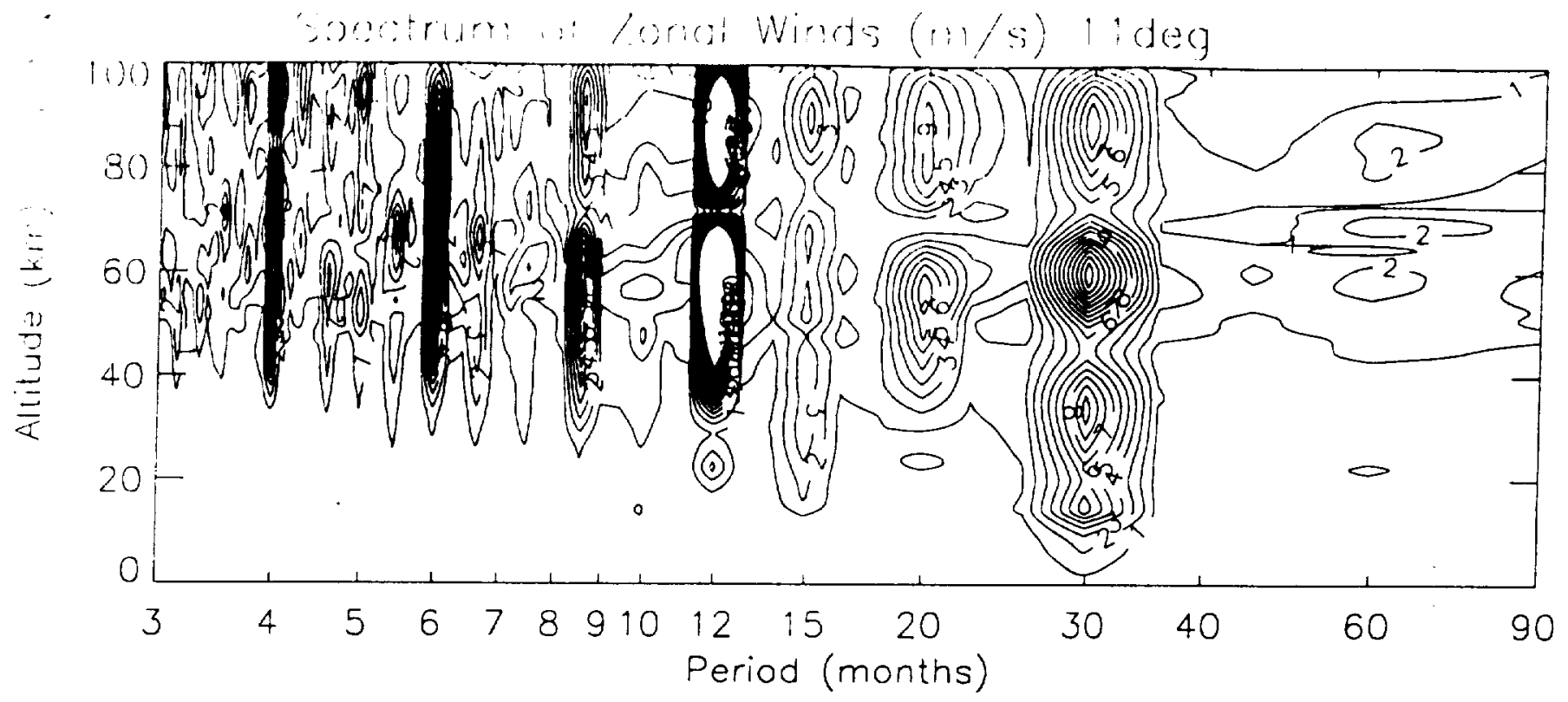

a

Spectrum of Zonal Winds $(\mathrm{m} / \mathrm{s}) 11 \mathrm{deg}$ symmetric

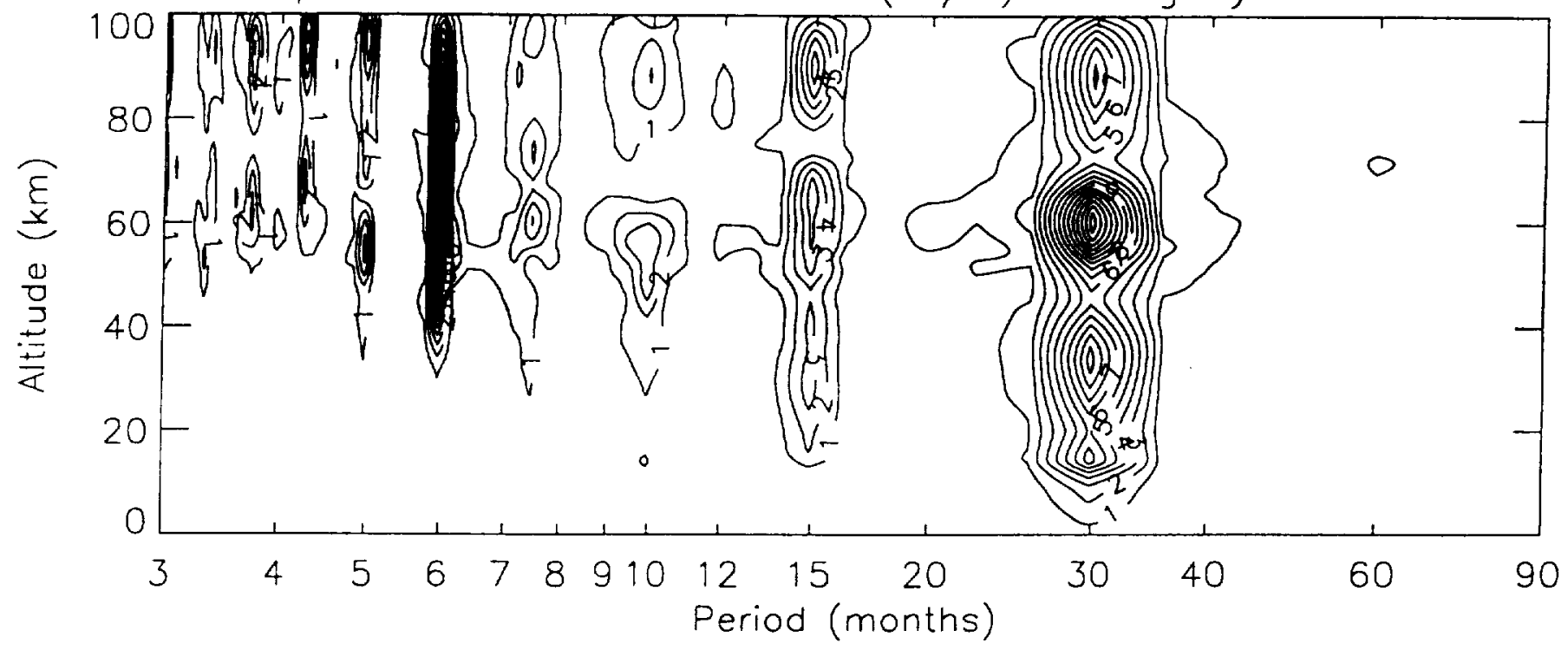

Spectrum of Zonal Winds $(\mathrm{m} / \mathrm{s}) 11$ deg a-symmetric

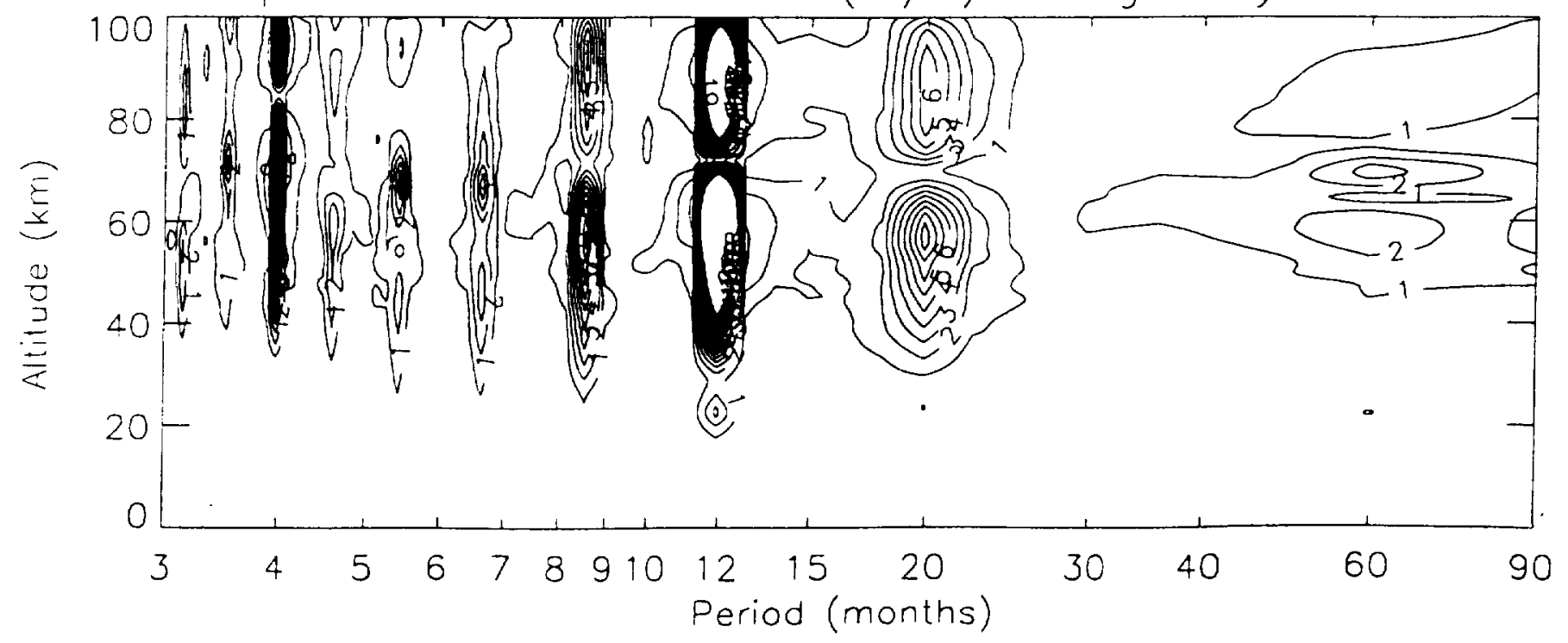

C

Figure 7 


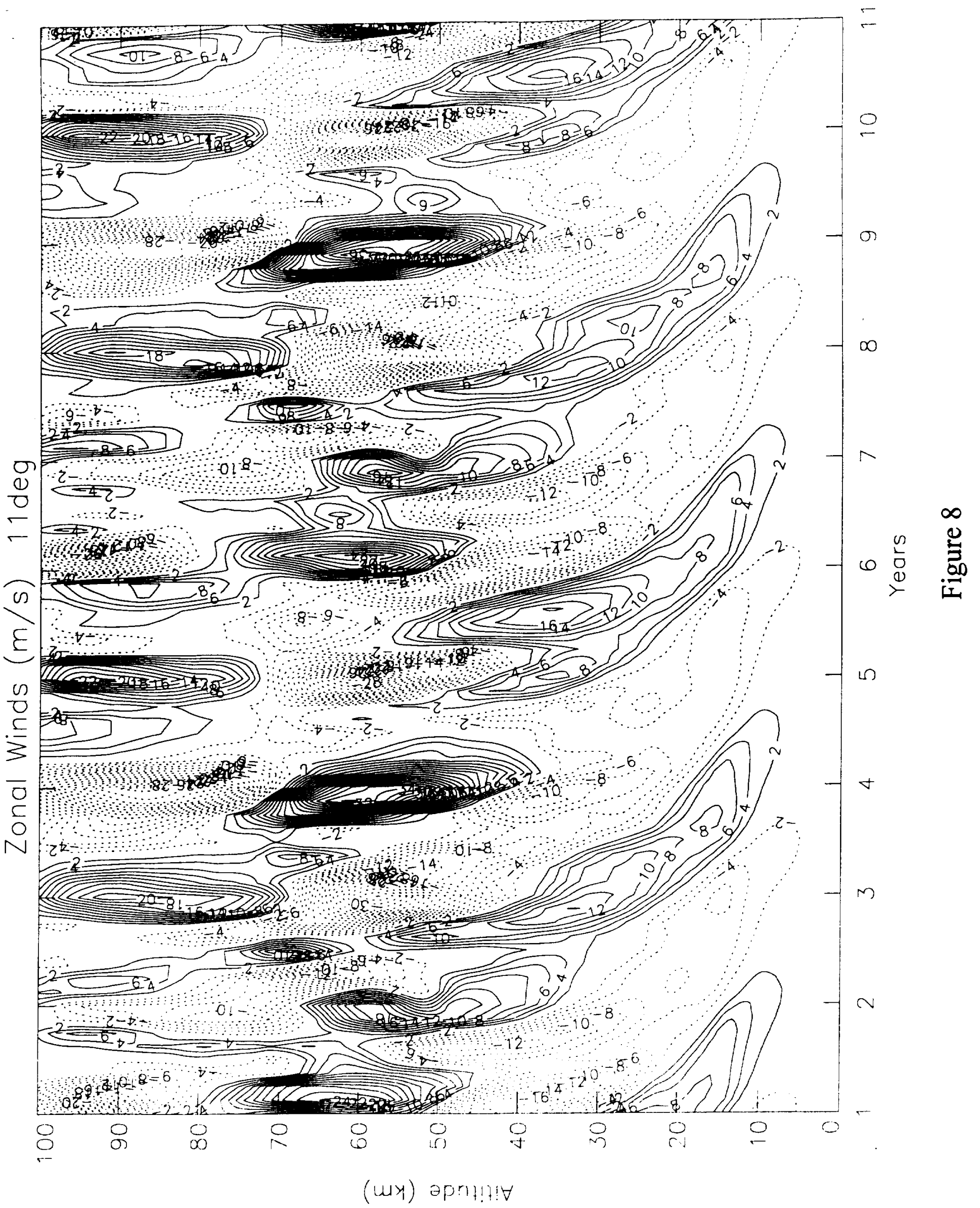




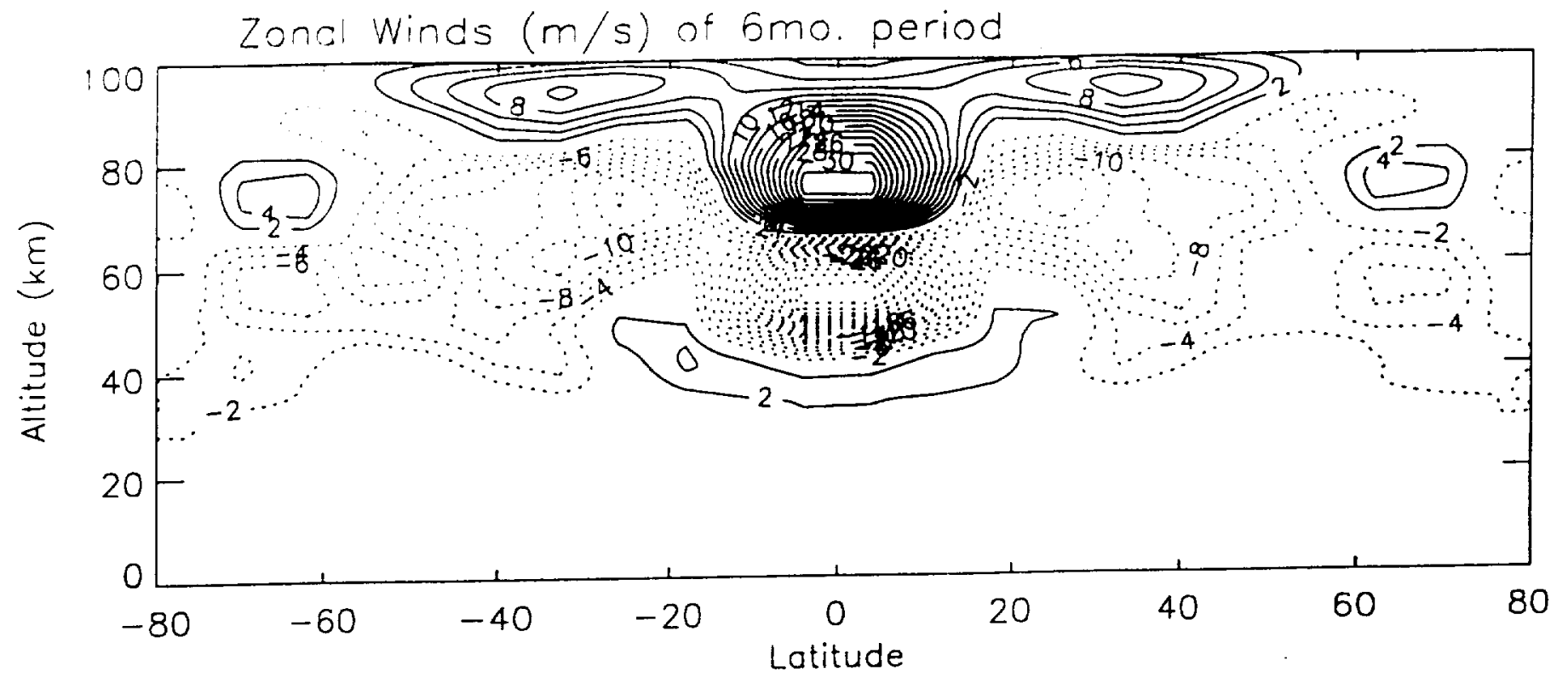

a

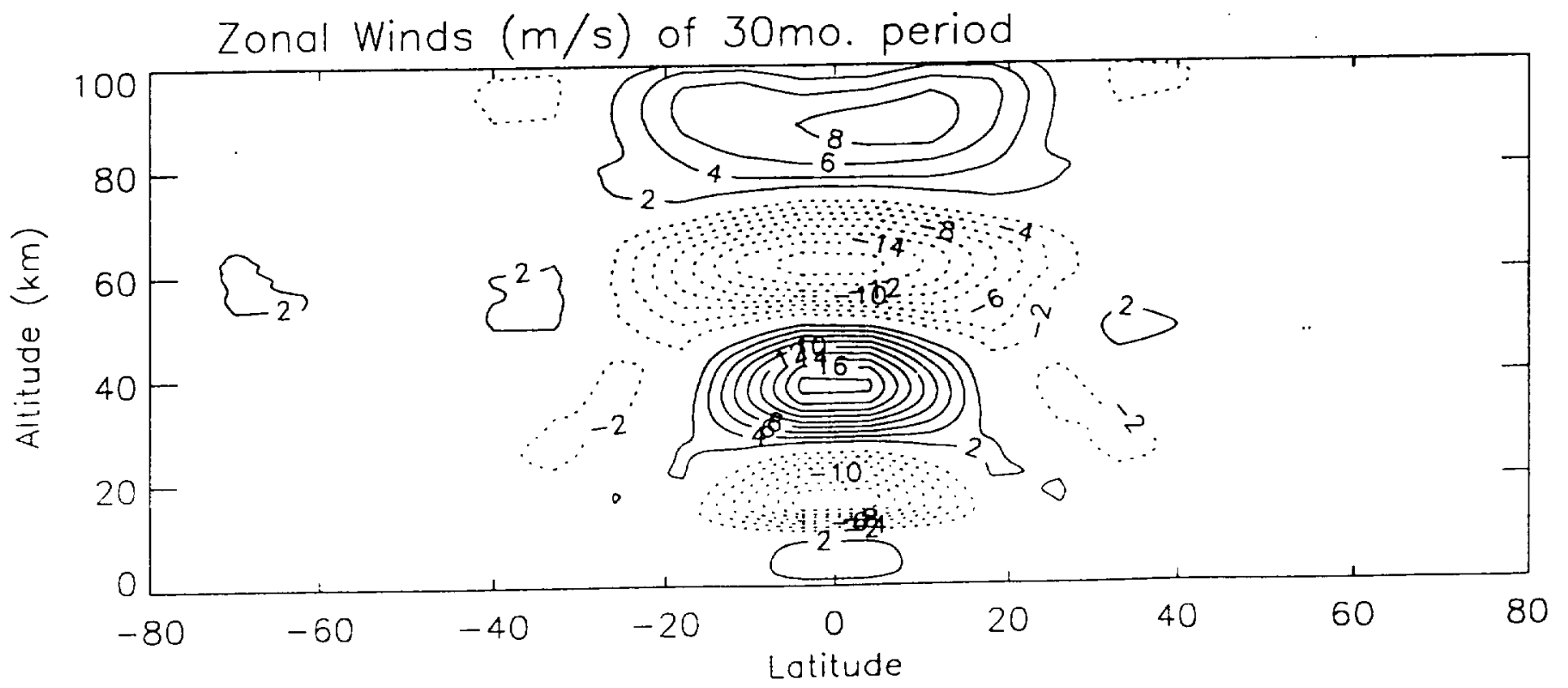

b

Figure 9 


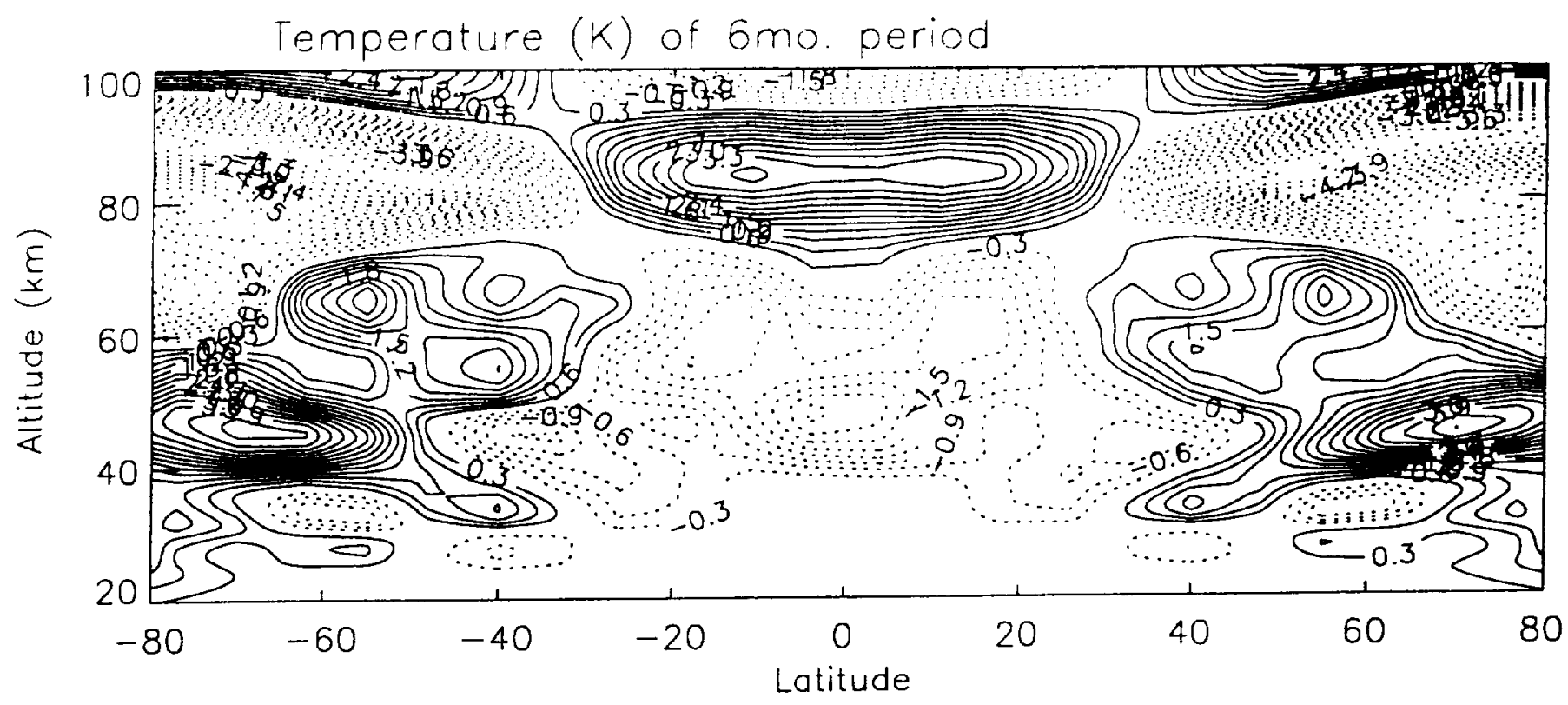

a

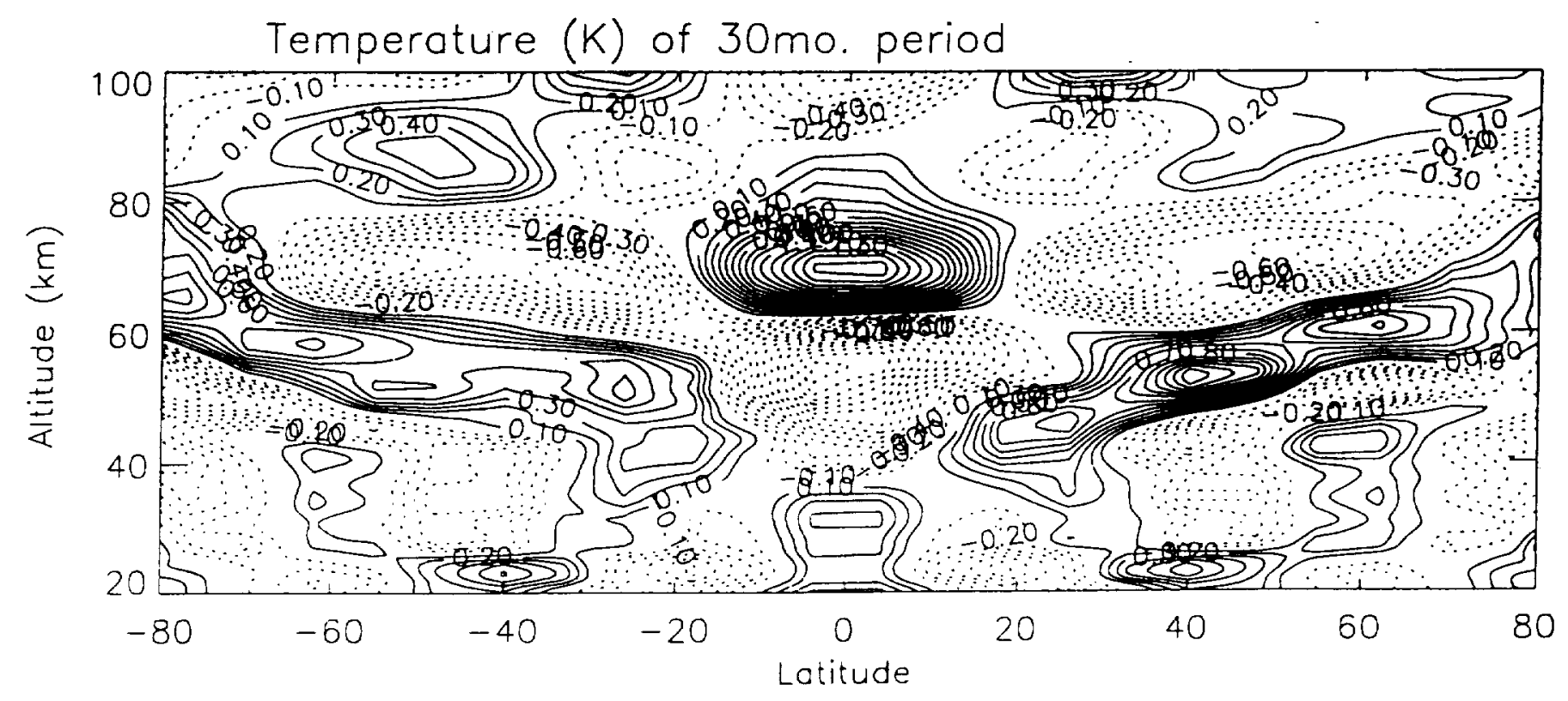

b

Figure 10 


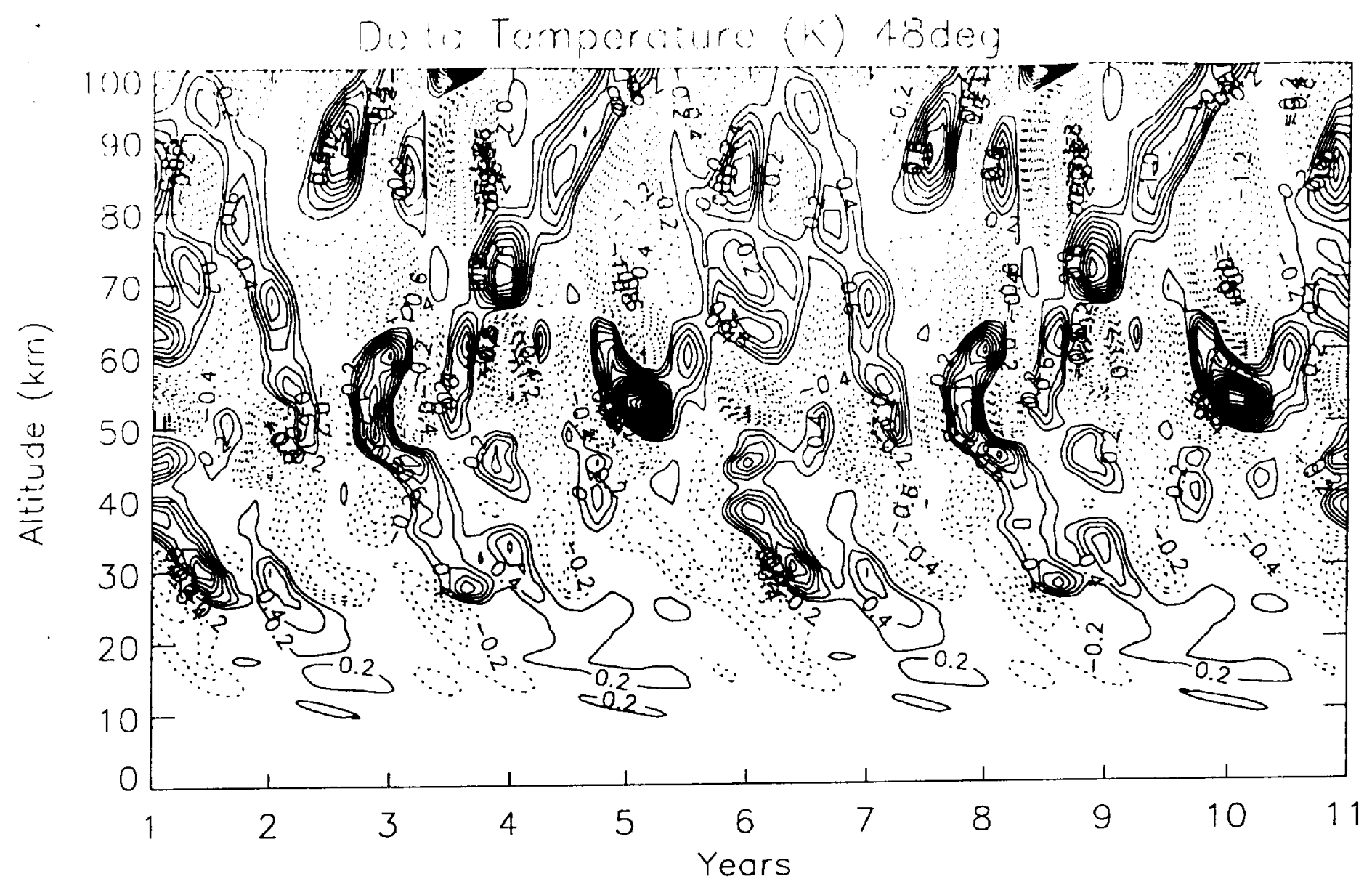

Figure 11 


\section{With Vertical Coriolis Force}

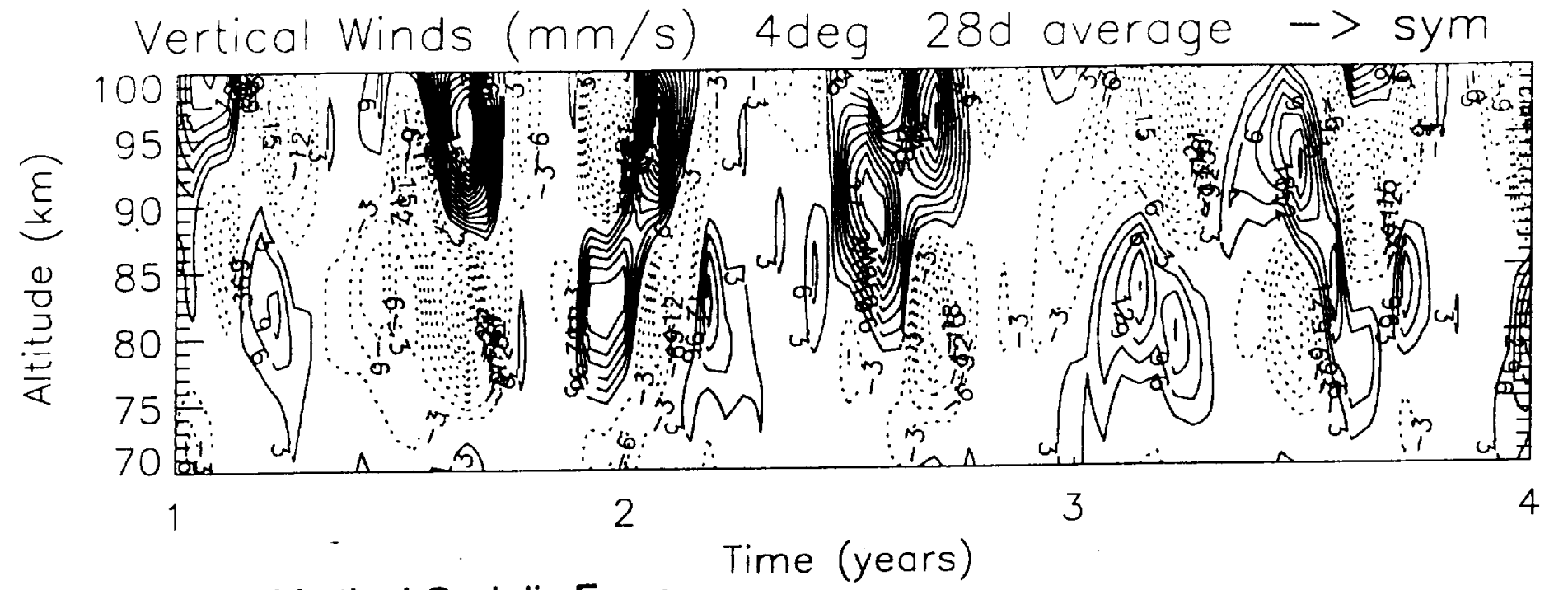

\section{Without Vertical Coriolis Force.}

Time (years)

\section{Vertical Winds $(\mathrm{mm} / \mathrm{s})$ 4deg $28 \mathrm{~d}$ average $\rightarrow$ sym}

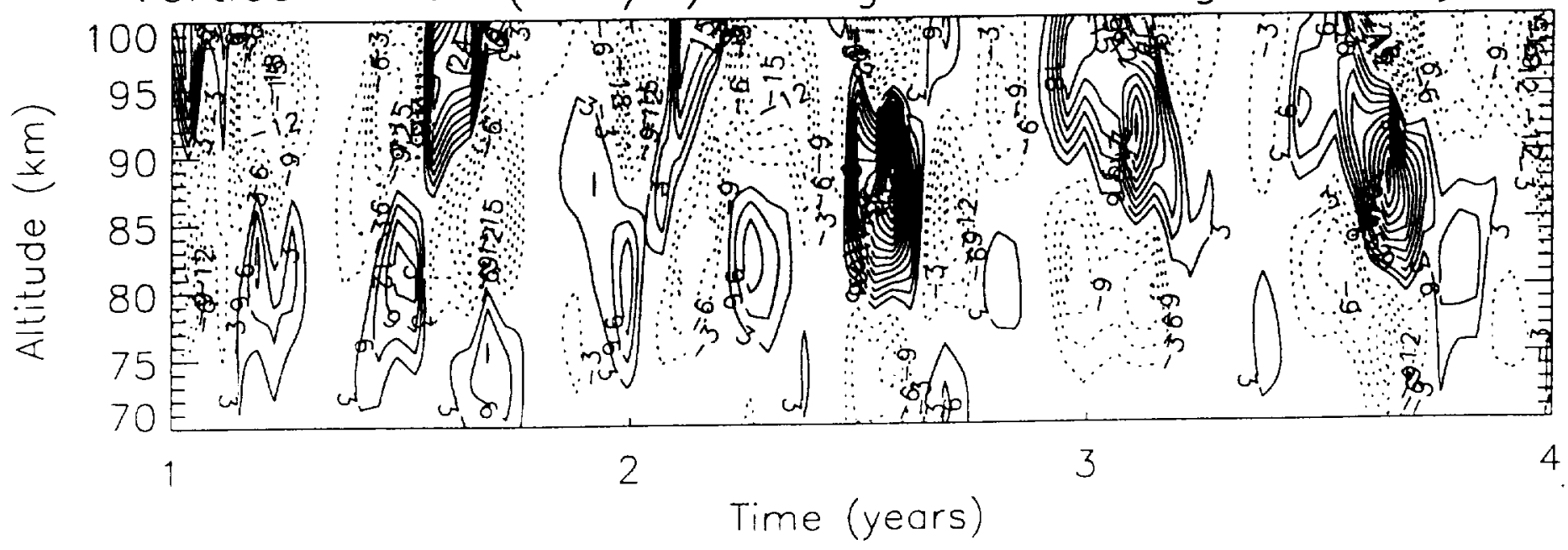

Figure 12 


\section{With Vertical Coriolis Force}

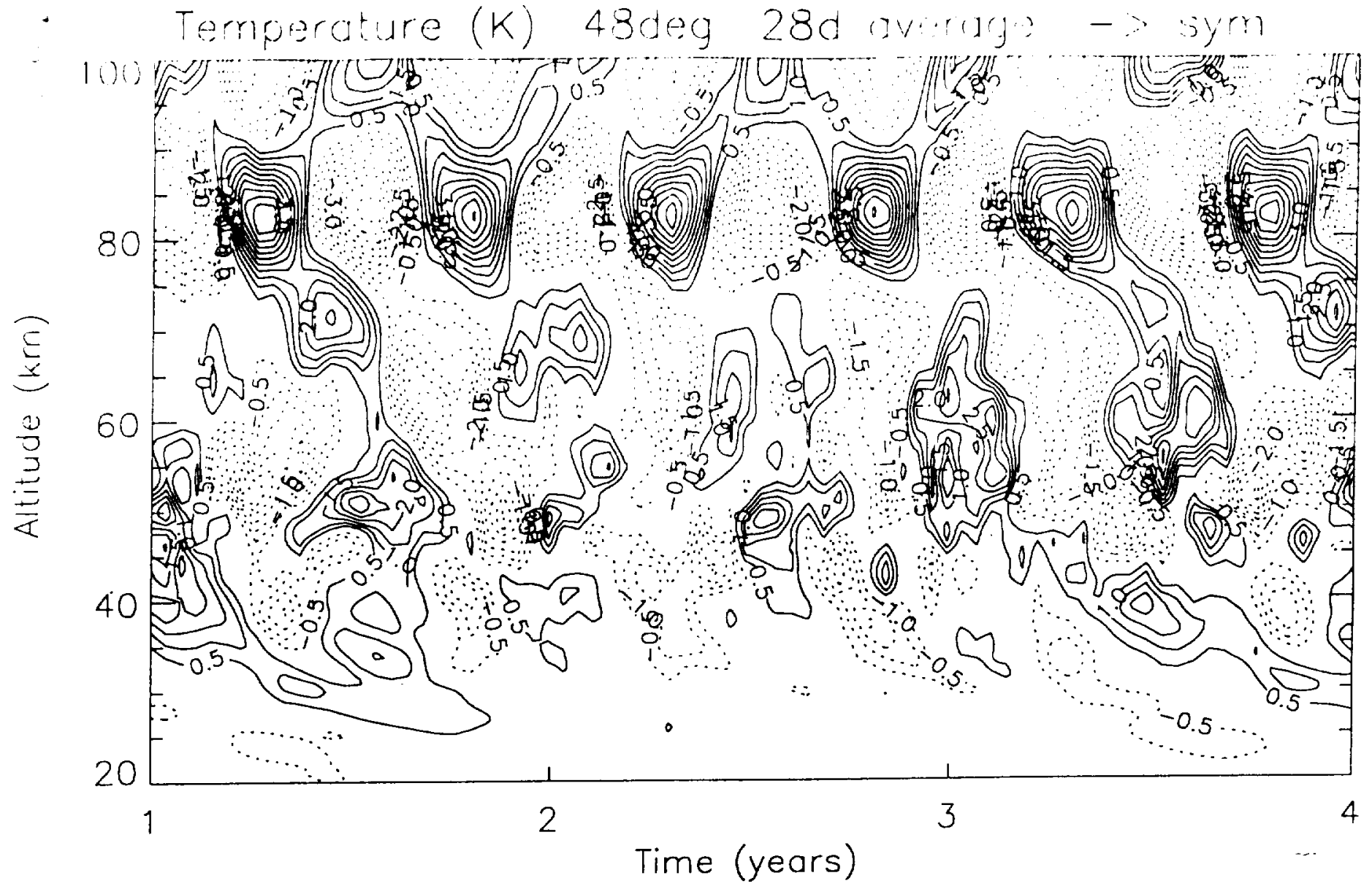

\section{Without Vertical Coriolis Force}

Temperature $(K)$ 48deg 28d average $->$ sym

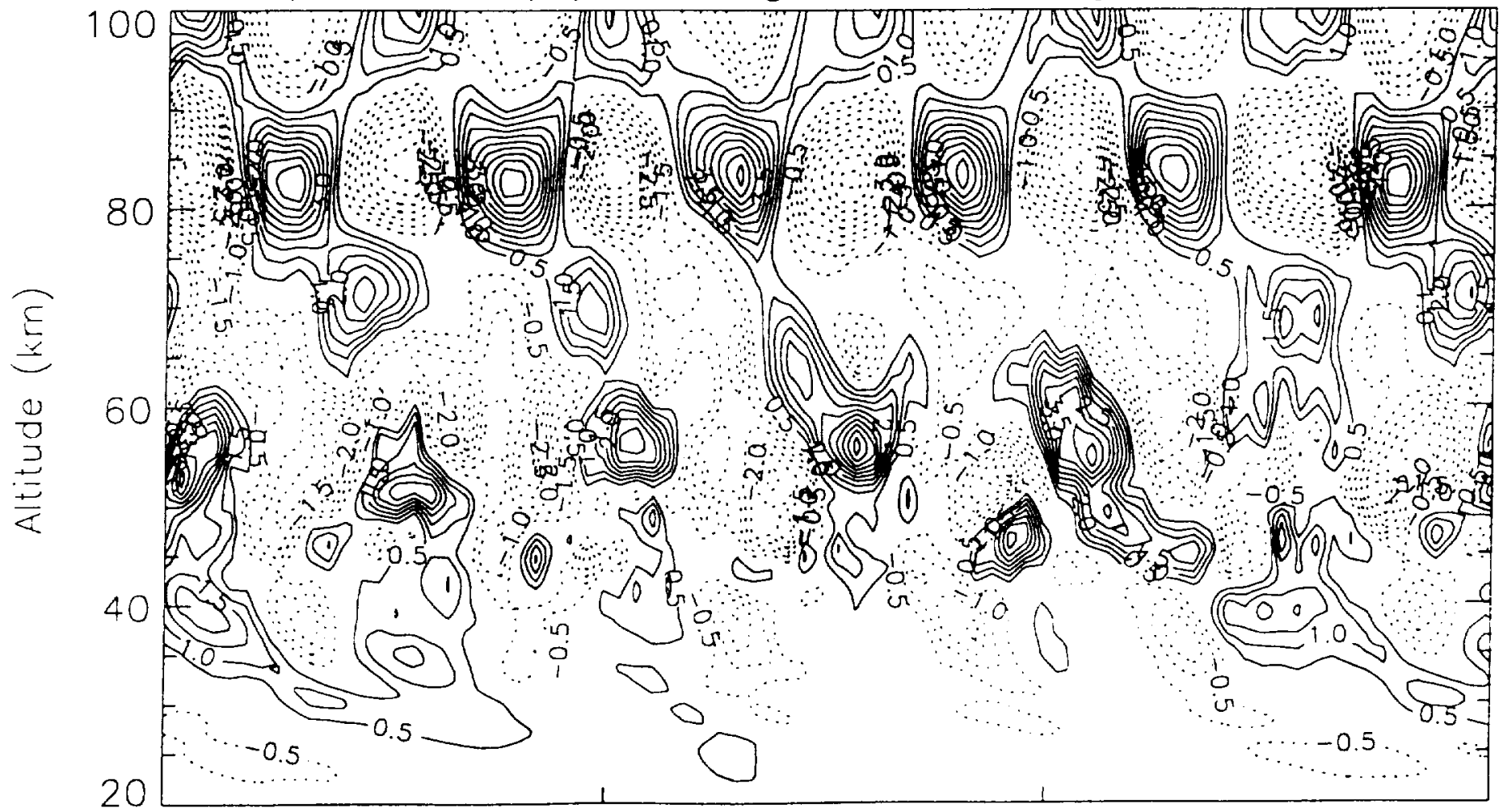

